\title{
Estructura térmica superficial del mar asociada a la distribución espacio-temporal de sardina y anchoveta en la zona norte de Chile entre 1987 y 1992 $^{1}$
}

\author{
Eleuterio Yáñez R., Antonio González C. y María Angela Barbieri B. ${ }^{2}$ \\ Escuela de Ciencias del Mar, Universidad Católica de Valparaíso \\ Casilla 1020, Valparaíso, Chile
}

RESUMEN. Utilizando un sistema de información geográfica (SIG), se analizan los cambios de la estructura térmica superficial del mar asociados a las variaciones espaciales y mensuales de sardina (Sardinops sagax) y anchoveta (Engraulis

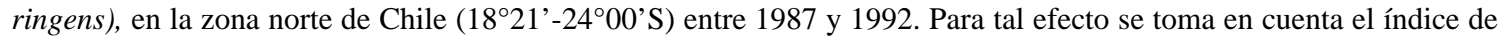
abundancia CPUE, estimado para ambas especies a partir de la información de una flota cerquera industrial. y datos de temperatura superficial del mar (TSM) recolectados con satélites NOAA. Además se analizan datos de TSM y nivel del mar de estaciones de mareógrafos, y de viento e insolación de estaciones meteorológicas.

En 1987 y 1992 la TSM presenta anomalías positivas asociadas a eventos El Niño, en tanto que 1990 se presenta como el año más frío del período de estudio. Se destaca la marcada señal anual de la TSM, con una estación cálida entre noviembre y abril, mientras que entre julio y septiembre se registran las TSM más bajas.

Al comparar las distribuciones anuales de CPUE se determinan diferencias significativas entre ambas especies. A su vez, cada especie presenta distribuciones de CPUE diferentes entre años. Las dos especies presentan un patrón de migración norte-sur de la estación fría a la estación cálida, el cual se alteraría cuando se producen fuertes anomalías de TSM.

Palabras claves: distribución, espacio-temporal, sardina, anchoveta, TSM satelital, norte de Chile, SIG.

\section{Sea surface thermal structure associated to the space-temporal distribution of sardine and anchovy in northern Chile}

\begin{abstract}
In order to establish the space-temporal variability of the distribution of the sardine (Sardinops sagax) and the anchovy (Engraulis ringens) in association with the sea surface thermal structure in northern Chile ( $\left.18^{\circ} 21^{\prime}-24^{\circ} 00^{\prime} \mathrm{S}\right)$, a study was conducted with satellite and fisheries data between 1987 and 1992. Information was processed by using a geographic information system (GIS). Variables considered in the analysis included the abundance index CPUE as estimated for both species from a purse seine industrial fleet data, satellite records of sea surface temperature (SST), tidal gauge temperature and sea level data, and insolation and wind data from meteorological stations.

In 1987 and 1992, the SST showed positive anomalies associated with El Niño events. The coldest year observed during the period of study was 1990. The SST annual signal is warmer between november and april, with the coldest records between july and september.

The annual distribution of the CPUE is significantly different among species and between years for an individual species. Nevertheless, the migration pattern for both species is similar, moving from north to south, from the cold season to the warmer season. The pattern is altered by strong SST anomalies.
\end{abstract}

Key words: distribution, time-space, sardine, anchovy, satellite SST, northern Chile, GIS.

1 Proyectos FONDECYT Nº 0481-92, DGI-UCV No223.749-93 y Patrocinio II Conferencia Espacial de las Américas, Santiago, Chile, 1993.

2 Dirección actual: Instituto de Fomento Pesquero, Huito 374, Valparaíso, Chile. 


\section{INTRODUCCION}

En Chile, después de la minería y la agricultura, la actividad pesquera juega un rol importante en la economía nacional. En este contexto, la pesquería pelágica de la zona norte $\left(18^{\circ} 21^{\prime}-24^{\circ} 00^{\prime} S\right)$ ha contribuido con el 57\% de los desembarques totales realizados en el país entre 1960 y 1992. En este período sobresalen las capturas de anchoveta (Engraulis ringens) hasta 1976 y posteriormente las de sardina (Sardinops sagax). No obstante, en los últimos años los desembarques de sardina han disminuido significativamente, en tanto que los de anchoveta presentan una notable recuperación (Martínez et al., 1992).

Esta pesquería ha sido analizada tomando en cuenta la evolución interanual del esfuerzo de pesca y la variabilidad de baja frecuencia del medio ambiente, con el objeto de comprender en mejor forma los cambios de largo plazo de la abundancia de los principales recursos explotados (Cañón, 1986; Yáñez y Barbieri, 1986; Yáñez, 1989; Cubillos y Fuenzalida, 1990; Yáñez, 1991).

Por otra parte, aunque algunos estudios se han desarrollado sobre la influencia de las variaciones del medio ambiente en la distribución espacial de dichos recursos (Cañón, 1978; Castillo y Guzmán, 1985; Castillo et al., 1995), se deduce la necesidad de estudios que favorezcan una comprensión más precisa en el espacio y en el corto plazo, tal como lo sugieren Csirke y Sharp (1984), Laurs (1989) y Barbieri (1991).

Con esta óptica, basados en información pesquera y oceanográfica satelital, además de datos oceanográficos y meteorológicos de estaciones ubicadas en la costa, se analizan las variaciones espacio-temporales de la estructura térmica superficial del mar y de la distribución de anchoveta y sardina en la zona norte de Chile entre 1987 y 1992, empleando un sistema de información geográfica (SIG).

\section{ANTECEDENTES}

Como consecuencia de profundos cambios en el ambiente físico y en la abundancia de peces neríticos, las principales pesquerías pelágicas costeras se desarrollan en ambientes particularmente dinámicos. Entender y predecir algunas de las reacciones de los peces a las variaciones del medio físico y las res- puestas de los ecosistemas a los cambios en la abundancia de los peces, resultaría útil en el proceso de toma de decisiones sobre medidas de manejo de tales pesquerías (Bernal et al., 1983; Csirke y Sharp, 1984; Yáñez y Barbieri, 1986; Bernal, 1990).

Los cambios del medio físico, como aquellos asociados al fenómeno El Niño, se caracterizan por desplazamientos importantes de las masas de agua. Muchos peces neríticos, como la anchoveta y la sardina, responden a estos cambios redistribuyéndose geográficamente en relación con la temperatura y otras características del agua. En este sentido, la información sinóptica de variables ambientales físicas puede ser útil para comprender el desplazamiento de los peces y las variaciones de sus áreas de distribución. Si el alimento es abundante, los peces alcanzan tasas más elevadas de crecimiento cuando la temperatura del agua es la preferida. Evidencias muestran que cuando el alimento es escaso, los peces se desplazan a temperaturas más frías para maximizar su crecimiento (Csirke y Sharp, 1984).

Las propiedades físicas de los mares influyen claramente en los procesos biológicos y en todas las escalas espacio-temporales (Mann, 1992). Dentro de las diferentes variables que afectan la distribución de los recursos pelágicos, la temperatura superficial del mar es considerada una de las más relevantes. Sus fluctuaciones a menudo representan señales de disturbios que se extienden en profundidad en los océanos (White y Walker, 1974). Además, ésta presenta la ventaja de ser una variable fácil de medir con satélites meteorológicos, con cuyos datos se pueden elaborar imágenes sinópticas de una amplia zona, en tiempo real y a bajo costo. Dichas imágenes han sido objeto de aplicaciones concretas en diferentes pesquerías (Barbieri et al., 1987,1989, 1991; Laurs, 1989; Le Gall, 1989),y recientemente en la pesquería pelágica de la zona norte de Chile (Yáñez et al., 1994).

Desde fines de la década de los sesenta la sardina experimentó un incremento en abundancia y una expansión en su distribución geográfica en el Pacífico suroriental (Serra y Tsukayama, 1988). Esto fue claramente evidenciado en la zona norte de Chile después del fenómeno El Niño de 1972-73, y más precisamente a partir de 1976 cuando se establece un período cálido de largo plazo (Yáñez, 1989; Cubillos y Fuenzalida, 1990).

De Buen (1960) considera que la subespecie Sardinops sagax musica se encuentra en el norte de 
Chile y Sardinops sagax sagax en la costa central y norte de Perú. Por su parte, Chirichigno et al. (1982) mencionan que esta última se encuentra total o parcialmente en las áreas de pesca ubicadas entre $1^{\circ} 39^{\prime} \mathrm{N}$ y $37^{\circ} \mathrm{S}$, mientras que la primera se localizaría sólo en el área de pesca comprendida entre $19^{\circ} 21^{\prime} \mathrm{S}$ y $37^{\circ} \mathrm{S}$. Dado lo anterior, existe la necesidad de determinar con mayor precisión los límites de la distribución de ambas subespecies. No se descarta la posibilidad de la existencia de dos subpoblaciones, cuya distribución habría sido más evidente cuando los niveles de abundancia de la especie eran bajos, estando actualmente confundidos debido al aumento de la abundancia y de la expansión geográfica (Serra y Tsukayama, 1988). No obstante, en el informe de la CPPS (1993) se asume la existencia de dos unidades de stock: una ubicada entre el sur de Ecuador y el centro-norte de Perú, y otra entre el sur de Perú y el norte de Chile. Por otra parte, Parrish et al. (1989) indican que las diferencias entre las poblaciones de Sardinops en los diversos sistemas de corrientes no justifican su separación en subespecies.

La anchoveta es una especie típicamente nerítica, que no sobrepasaría los $50 \mathrm{~m}$ de profundidad y que se distribuye en Perú y en Chile entre los 4³0'S y 42³0'S (Serra et al., 1979). Estudios biológicos indicarían la existencia de tres unidades poblacionales, ubicadas en el norte-centro de Perú, el sur de Perú y norte de Chile, y el centro-sur de Chile (Serra, 1983).

La pesquería de anchoveta en la zona norte de Chile ha sido evaluada en forma independiente (Serra, 1986; Yáñez et al., 1986). En Perú, las evaluaciones se centran en el stock norte-centro ( $4^{\circ}$ $\left.14^{\circ} \mathrm{S}\right)$, considerándolo separado del stock del sur del Perú y norte de Chile (Pauly y Tsukayama, 1987; CPPS, 1993). Sin embargo, como las evidencias en este sentido no son suficientemente claras, también se han realizado evaluaciones considerando en conjunto las pesquerías de anchoveta de Perú y norte de Chile (Yáñez, 1989, 1991).

\section{MATERIALES Y METODOS}

La información satelital disponible consistió en 1.868 imágenes diarias de temperatura superficial del mar (TSM), elaboradas con información captada a través del sensor AVHRR de satélites NOAA. Esta información es recepcionada, procesada y puesta a disposición de los usuarios por el Centro de Estudios Espaciales de la Universidad de Chile (Barbieri et al., 1989b). Estas imágenes cubren el período 1987 92 , y la zona comprendida entre los $18^{\circ} 00^{\prime} \mathrm{S}$ y $23^{\circ} 30^{\prime} \mathrm{S}$, desde la costa hasta los $73^{\circ} \mathrm{W}$.

Las imágenes representan matrices de datos de TSM de 256 líneas por 256 columnas, con una resolución de 2,2 km en el sentido norte-sur y de 1,6 $\mathrm{km}$ en dirección este-oeste, en escala 1:2.000.000. Del total de imágenes diarias de TSM disponibles (1.868), se consideró sólo el $69 \%$ en los análisis posteriores (Tabla 1). Las imágenes restantes no fueron utilizadas debido a la gran cobertura de nubes que registran. La interferencia de las nubes, analizada en detalle por Barbieri et al. (1995), explica principalmente la menor cantidad de imágenes utilizadas de mayo a septiembre. Por otro lado, limitaciones del formato de almacenamiento implicaron que la información no estuviera igualmente disponible para los años 1987 y 1988, lo que se refleja en el menor número de imágenes utilizadas.

Además, para reducir el efecto de las nubes que se registran en las imágenes diarias seleccionadas

Tabla 1. Imágenes diarias de TSM satelitales utilizadas en el análisis de la estructura térmica superficial del mar en la zona norte de Chile.

\begin{tabular}{|c|c|c|c|c|c|c|c|c|c|c|c|c|c|}
\hline \multirow{2}{*}{ Años } & \multicolumn{12}{|c|}{ Meses } & \multirow{2}{*}{ Total } \\
\hline & ENE & FEB & MAR & $\mathrm{ABR}$ & MAY & JUN & JUL & AGO & SEP & OCT & NOV & DIC & \\
\hline 1987 & 16 & 18 & 17 & 15 & 8 & 2 & 3 & 11 & 11 & 14 & 11 & 17 & 143 \\
\hline 1988 & 19 & 21 & 4 & 17 & 15 & 8 & 8 & 8 & 8 & 15 & 19 & 18 & 160 \\
\hline 1989 & 29 & 24 & 31 & 16 & 21 & 12 & 9 & 19 & 21 & 26 & 23 & 27 & 258 \\
\hline 1990 & 27 & 22 & 24 & 26 & 14 & 16 & 8 & 14 & 15 & 15 & 21 & 16 & 218 \\
\hline 1991 & 28 & 24 & 27 & 22 & 19 & 18 & 16 & 14 & 14 & 28 & 23 & 26 & 259 \\
\hline 1992 & 22 & 27 & 24 & 23 & 22 & 15 & 20 & 18 & 22 & 20 & 24 & 22 & 259 \\
\hline Total & 141 & 136 & 127 & 119 & 99 & 71 & 64 & 84 & 91 & 118 & 121 & 126 & 1.297 \\
\hline
\end{tabular}


(1.297), en el análisis de la estructura térmica superficial se considera el valor máximo de la TSM mensual por pixel (TSMM) (Pettigiani et al., 1992). En efecto, estas imágenes diarias se georreferenciaron y a través de superposiciones de las de cada mes se extraen los valores de TSMM de cada pixel, generando así imágenes mensuales de TSMM. Luego, por superposición de estas imágenes mensuales se crean imágenes promedios anuales de TSMM.

De las estaciones de mareógrafos y meteorológicas ubicadas en Arica ( $\left.18^{\circ} 28^{\prime} \mathrm{S}\right)$, Iquique ( $20^{\circ} 12^{\prime} \mathrm{S}$ ) y Antofagasta ( $\left.23^{\circ} 39^{\prime} \mathrm{S}\right)$, se recuperaron los registros diarios de TSM, nivel del mar, insolación, fuerza y dirección del viento. A partir de estos datos se estimaron los promedios mensuales de dichas variables, con el objeto de analizar estadísticamente sus tendencias y estacionalidades.

La información pesquera proviene de las bitácoras de pesca de 31 embarcaciones cerqueras industriales que operan desde los puertos de Arica, Iquique, Tocopilla $\left(22^{\circ} \mathrm{S}\right)$ y Mejillones $\left(23^{\circ} \mathrm{S}\right)$. Con una resolución espacial de 10 x 10 mn, las bitácoras de cada barco indican las capturas diarias por especie. En base al estudio de Yáñez et al. (1993), se trabajó con el índice de abundancia CPUE estimado para anchoveta y sardina por día y cuadrícula de 10 x $10 \mathrm{mn}$, en toneladas por día de pesca estándar (t/dpe). Las CPUE se georreferenciaron y promediaron, creando imágenes de CPUE promedios mensuales con una resolución de 10 x $10 \mathrm{mn}$, a las cuales se les determinó el centro de gravedad (CG). Por otra parte, las imágenes de distribución espacial de CPUE promedios anuales de anchoveta y sardina presentadas por Yáñez et al. (1993), se compararon empleando como medida de asociación el índice V de Cramer (IVC) (Ott et al., 1983). Finalmente se analizaron estadísticamente los desembarques y CPUE promedios de las cartografías mensuales, considerando sus tendencias y estacionalidades.

El procesamiento y análisis de la información se realizó a través del SIG IDRISI 4.0 (Eastman, 1992) y del programa estadístico STATGRAPHICS.

\section{RESULTADOS Y DISCUSION}

\section{Variabilidad espacio-temporal de la TSM}

En las imágenes de TSMM se observa una vidente variabilidad intra e interanual de la estructura térmica superficial del mar en la zona de estudio (Fig. 1). Se destaca la marcada señal anual, con una estación cálida que se inicia en noviembre y que termina en abril, en tanto que desde julio a septiembre se registran las temperaturas más bajas. Se puede apreciar que en las imágenes se registra un cierto grado de cobertura de nubes, especialmente en el período frío, lo cual implica que el empleo de la TSMM no elimina totalmente este tipo de interferencia.

En 1987 se produce el evento El Niño, lo cual implica que en la zona se presentan a partir de febrero las anomalías positivas de temperatura más importantes del período de estudio (Fig. 2a). En 1992 se produce otro fenómeno El Niño, el cual se manifiesta con importantes anomalías positivas de temperatura a partir de marzo. Los meses de noviembre y diciembre de 1989, y enero de 1990, son también particularmente cálidos. Por el contrario, durante el resto de los meses de 1990 se producen las anomalías negativas de temperatura más importantes del período (Fig. 2a), asociadas probablemente al fenómeno denominado La Niña (Philander, 1990). De esta manera, los promedios anuales de TSMM señalan que los años 1987 y 1992 resultan los más cálidos del período analizado, y el de 1990 el más frío (Fig. $2 b)$.

La estacionalidad y tendencia de la TSMM promedio mensual estimada a partir de datos de satélites NOAA (Fig. 2a y b), muestran un comportamiento análogo a las de la TSM promedio mensual de las estaciones de mareógrafos (Fig. 3a y b), no obstante sus diferencias en magnitud y amplitud. Se destacan las altas TSM registradas entre marzo y mayo de 1992 en esas estaciones, implicando un especial calentamiento de la zona costera.

En el modo espacial se observan durante la estación cálida (noviembre-abril), diferencias de hasta $4^{\circ} \mathrm{C}$ de temperatura entre la parte norte y sur de la zona de estudio (Fig. 1). Estas diferencias y la estacionalidad de la TSMM se asocian a la intrusión desde el noroeste hacia la costa de aguas cálidas, la cual se intensifica durante los eventos El Niño. Al respecto, cabe señalar que las variaciones interanuales del nivel del mar en la zona de Arica (Fig. 4), definida como estable desde el punto de vista oceanográfico (Bakun y Parrish, 1982), resultan similares a las de la TSM (Figs. 2b y 3b). No obstante, el calentamiento de la superficie del mar también se relaciona con 
la marcada señal anual de la insolación (Fig. 5), al presentar un comportamiento análogo al de la TSM (Fig. 3a).

En la costa se pueden apreciar lugares característicos de menores temperaturas (Fig. 1), que se asocian a eventos de surgencia producidos por vientos locales del sur y suroeste que predominan en la zona durante todo el año, con valores máximos en primavera-verano (Pizarro et al., 1994). Bravo (1993) y Barbieri et al. (1995) analizan la TSM registrada con satélites NOAA entre la costa y los $16 \mathrm{~km}$, indicando la existencia de 8 focos de surgencia ubicados frente a puntas sobresalientes de la zona de estudio. La intensidad de las surgencias es mayor en verano y menor en invierno, lo que coincide con la estacionalidad de la componente $\mathrm{N}-\mathrm{S}$ del viento en las estaciones meteorológicas (Fig. 6). Estos eventos, que tienen lugar en una estrecha banda costera equivalente a un radio de deformación de Rossby, junto a la advección de aguas de altas latitudes, proporcionan los nutrientes que sustentan los altos niveles de producción biológica del Pacífico suroriental (Bernal et al., 1983).

\section{Variaciones de los desembarques mensuales de sardina y anchoveta}

Las pesquerías de anchoveta y sardina de la zona norte de Chile son sometidas a vedas extractivas relacionadas con los períodos de mayor actividad reproductiva de ambos recursos y de reclutamiento en el caso de la ancho veta (Tabla 2). Estas vedas, como se verá más adelante, afectan los niveles de captura y el carácter muestreador de la flota cerquera industrial durante los meses claves. No obstante, durante los períodos de veda se autoriza la captura para carnada y elaboración de productos para consumo humano, y la realización de muestreos biológicos con barcos de dicha flota (Cañón, 1990a, 1990b).

La serie desestacionalizada de los desembarques mensuales de sardina muestra una tendencia a la disminución desde mediados de 1989 (Fig. 7a). Los mayores desembarques de 1987 y la recuperación que se insinúa entre 1991 y 1992, se relacionan con la distribución más costera deltecurso durante eventos El Niño (Yáñez et al., 1994). La componente estacional de los desembarques muestra los efectos de las vedas reproductivas en las capturas de febrero y agosto (Fig. 7b).

Los desembarques mensuales desestacionalizados de anchoveta, desde los valores mínimos de 1987 asociados a los efectos del fenómeno El Niño, pre- sentan una tendencia creciente hasta 1989. Luego éstos disminuyen y tienden a estabilizarse hasta el final del período de estudio, con algunos valores sobresalientes durante El Niño de 1992 (Fig. 8a). La señal anual de dichos desembarques indica los efectos de las vedas extractivas en los niveles de captura de enero, febrero, agosto, septiembre y diciembre (Fig. 8b).

\section{Variabilidad espacio-temporal de la CPUE aso- ciada a cambios de la TSM}

Yáñez et al. (1993) analizan la distribución espacial e interanual de sardina y anchoveta en la zona norte de Chile (1987-92), e indican que los CG de las cartografías anuales de CPUE no se sobreponen, dado que los de sardina se ubican más lejos de la costa. Al comparar dichas cartografías anuales de CPUE a través del IVC no se establecen evidencias que indiquen que las distribuciones de ambas especies sean iguales, dado que los valores son inferiores a 0,32 (Tabla 3 ).

En efecto, dichas cartografías muestran que la ancho veta se distribuye preferentemente dentro de las primeras $60 \mathrm{mn}$ de la costa, aunque en ocasiones sobrepasa este límite en la parte norte de la zona de estudio. Sin embargo, los valores más importantes

Tabla 2. Vedas extractivas de anchoveta y sardina durante el período de estudio en el norte de Chile.

\begin{tabular}{|c|c|c|}
\hline Año & Anchoveta & Sardina \\
\hline 1987 & Sin veda & $\begin{array}{l}01 \text { FEB - } 25 \text { FEB } \\
01 \text { AGO - } 11 \text { SEP }\end{array}$ \\
\hline 1988 & $\begin{array}{c}23 \text { ENE - } 31 \text { MAR } \\
01 \text { AGO - } 11 \text { SEP } \\
19 \text { DIC - } 31 \text { DIC }\end{array}$ & $\begin{array}{l}01 \mathrm{FEB}-11 \mathrm{MAR} \\
01 \mathrm{AGO}-11 \mathrm{SEP}\end{array}$ \\
\hline 1989 & $\begin{array}{c}01 \mathrm{ENE} \text { - } 19 \mathrm{MAR} \\
31 \mathrm{JUL}-29 \mathrm{SEP} \\
25 \mathrm{DIC}-31 \mathrm{DIC}\end{array}$ & $\begin{array}{l}20 \text { ENE - } 28 \text { FEB } \\
17 \text { JUL - } 24 \text { SEP }\end{array}$ \\
\hline 1990 & $\begin{array}{c}01 \mathrm{ENE} \text { - } 18 \mathrm{MAR} \\
30 \mathrm{JUL} \text { - } 01 \mathrm{SEP} \\
10 \mathrm{DIC} \text { - } 31 \mathrm{DIC}\end{array}$ & $\begin{array}{l}22 \mathrm{ENE} \text { - } 04 \mathrm{MAR} \\
16 \mathrm{JUL} \text { - 08 SEP }\end{array}$ \\
\hline 1991 & $\begin{array}{c}01 \mathrm{ENE} \text { - } 07 \mathrm{MAR} \\
10 \mathrm{DIC}-31 \mathrm{DIC}\end{array}$ & Sin veda \\
\hline 1992 & $\begin{array}{l}01 \mathrm{ENE}-29 \mathrm{FEB} \\
10 \mathrm{AGO}-17 \mathrm{SEP} \\
30 \mathrm{NOV}-31 \mathrm{DIC}\end{array}$ & $\begin{array}{l}27 \text { ENE - 07 MAR } \\
17 \text { AGO - } 26 \text { SEP }\end{array}$ \\
\hline
\end{tabular}

Fuente: Subsecretaría de Pesca 
Tabla 3. Comparación de las distribuciones anuales de CPUE de sardina y de anchoveta en la zona norte de Chile (1987-92) a través del ínidice V de Cramer (IVC).

\begin{tabular}{|c|c|c|c|c|}
\hline Años & IVC & g.l. & Chi $^{2}$ estimado & Chi $^{2}$ tabla \\
\hline 1987 & 0,18 & 12 & 62 & 21 \\
1988 & 0,23 & 16 & 133 & 26 \\
1989 & 0,24 & 16 & 149 & 26 \\
1990 & 0,31 & 12 & 182 & 21 \\
1991 & 0,17 & 16 & 71 & 26 \\
1992 & 0,28 & 16 & 208 & 26 \\
\hline
\end{tabular}

g.l. = grados de libertad

de CPUE se ubican dentro de las primeras $20 \mathrm{mn}$, en sectores característicos que se asocian a focos permanentes de surgencia (Yáñez et al., 1994). La sardina presenta una distribución más amplia, encontrandose hasta los $73^{\circ} \mathrm{W}$.

Al comparar las distribuciones anuales de CPUE de sardina a través del IVC se establecen diferencias entre sí (Tabla 4). Esto mismo sucede al comparar entre sí las cartografías anuales de CPUE de anchoveta (Tabla 5). Estas diferencias se deberían a variaciones de abundancia de los recursos y a los efectos de las modificaciones de la estructura tér- mica superficial del mar. En efecto, durante los eventos El Niño ambas especies presentan distribuciones más costeras y en los últimos años del período 1987-92 se habrían producido notables disminuciones de abundancia, particularmente de sardina (Yáñez et al., 1993, 1994).

Variaciones espaciales y mensuales de la CPUE de sardina

En las Figuras 9a y 9b se muestra la distribución espacial y mensual de la CPUE de sardina, representando con mayor intensidad de color los valores más importantes. Se destaca la menor información de los meses afectados por las vedas extractivas (señalados con la sigla VE), y de aquellos meses en que toda la flota cerquera industrial de la zona norte registra bajas capturas de sardina (indicados con el signo ?).

En 1991, el desembarque total de sardina fue el menor del período analizado (Tabla 6a), debido principalmente a los bajos niveles logrados entre enero y julio, relacionados con la tendencia a la disminución observada desde mediados de 1989 (Fig. 7a). Estos bajos niveles de captura se deberían al importante grado de desconcentración que habría presentado el recurso en 1991, asociado a una disminución de su abundancia y/o disponibilidad (Yáñez et al., 1993).

Tabla 4. Comparación de las distribuciones anuales de CPUE de sardina en la zona norte de Chile a través del índice V de Cramer (IVC).

\begin{tabular}{|c|c|r|r|r|r|r|}
\hline \multicolumn{2}{|c|}{ Años } & 1988 & 1989 & 1990 & 1991 & 1992 \\
\hline \multirow{2}{*}{1987} & IVC & 0,28 & 0,30 & 0,25 & 0,11 & 0,28 \\
& $\mathrm{Chi}^{2}$ & 201 & 235 & 126 & 31 & 205 \\
& g.1. & 16 & 16 & 16 & 16 & 16 \\
\hline \multirow{2}{*}{1988} & IVC & & 0,24 & 0,23 & 0,12 & 0,20 \\
& $\mathrm{Chi}^{2}$ & & 148 & 101 & 34 & 101 \\
& g.1. & & 16 & 12 & 16 & 16 \\
\hline \multirow{2}{*}{1989} & IVC & & & 0,33 & 0,09 & 0,19 \\
& Chi $^{2}$ & & & 217 & 20 & 95 \\
& g.1. & & & 12 & 16 & 16 \\
\hline \multirow{2}{*}{1990} & IVC & & & & 0,12 & 0,25 \\
& Chi & & & 29 & 123 \\
& g.1. & & & & 12 & 12 \\
\hline \multirow{2}{*}{1991} & IVC & & & & & 0,19 \\
& Chi & & & & 93 \\
& g.l. & & & & & 16 \\
\hline
\end{tabular}

g.l. = grados de libertad 
No obstante, lo sucedido en 1991 habría favorecido el mayor desembarque realizado en el puerto de Arica durante este año (Tabla 6a). El análisis de las cartografías anuales de CPUE de sardina (198792) muestra que el CG del mapa de 1991 es el que se ubica más al norte y sobre todo más alejado de la costa. En 1992 se aprecia una cierta recuperación de la cobertura espacial de la CPUE con 165 cuadrículas con capturas, en comparación con las 101 de 1991, lo cual se relacionaría con un aumento de la disponibilidad que habría presentado el recurso producto del fenómeno El Niño (Yáñez et al., 1993).

Sin considerar los meses más afectados por las vedas extractivas (febrero y agosto), la señal desestacionalizada de la CPUE promedio de las car-

Tabla 5. Comparación de las distribuciones anuales de CPUE de anchoveta en la zona norte de Chile a través del índice V de Cramer (IVC).

\begin{tabular}{|c|c|c|c|c|c|c|}
\hline \multicolumn{2}{|c|}{ Años } & 1988 & 1989 & 1990 & 1991 & 1992 \\
\hline 1987 & $\begin{array}{l}\text { IVC } \\
\mathrm{Chi}^{2} \\
\text { g.l. }\end{array}$ & $\begin{array}{c}0,31 \\
188 \\
12\end{array}$ & $\begin{array}{c}0,31 \\
179 \\
12\end{array}$ & $\begin{array}{c}0,28 \\
154 \\
12\end{array}$ & $\begin{array}{c}0,25 \\
119 \\
12\end{array}$ & $\begin{array}{r}0,26 \\
127 \\
12\end{array}$ \\
\hline 1988 & $\begin{array}{l}\text { IVC } \\
\mathrm{Chi}^{2} \\
\text { g.1. }\end{array}$ & & $\begin{array}{r}0,35 \\
310 \\
16\end{array}$ & $\begin{array}{r}0,29 \\
221 \\
16\end{array}$ & $\begin{array}{r}0,26 \\
176 \\
16\end{array}$ & $\begin{array}{r}0,22 \\
121 \\
16\end{array}$ \\
\hline 1989 & $\begin{array}{l}\text { IVC } \\
\mathrm{Chi}^{2} \\
\text { g.1. }\end{array}$ & & & $\begin{array}{r}0,38 \\
369 \\
16\end{array}$ & $\begin{array}{c}0,30 \\
229 \\
16\end{array}$ & $\begin{array}{c}0,34 \\
302 \\
16\end{array}$ \\
\hline 1990 & $\begin{array}{l}\text { IVC } \\
\mathrm{Chi}^{2} \\
\text { g.l. }\end{array}$ & & & & $\begin{array}{c}0,30 \\
233 \\
16\end{array}$ & $\begin{array}{r}0,33 \\
274 \\
16\end{array}$ \\
\hline 1991 & $\begin{array}{l}\text { IVC } \\
\mathrm{Chi}^{2} \\
\text { g.l. }\end{array}$ & & & & & $\begin{array}{r}0,41 \\
440 \\
16\end{array}$ \\
\hline
\end{tabular}

g.l. = grados de libertad

Tabla 6. Desembarques anuales ( $t$ ) en los principales puertos del área de estudio: a) sardina y b) anchoveta.

\begin{tabular}{|c|c|c|c|c|c|}
\hline Año & Arica & Iquique & Tocopilla & Mejillones & Total \\
\hline \multicolumn{6}{|c|}{ a) sardina } \\
\hline $\begin{array}{l}1987 \\
1988 \\
1989 \\
1990 \\
1991 \\
1992\end{array}$ & $\begin{array}{l}539.075 \\
349.087 \\
359.555 \\
196.070 \\
310.757 \\
245.716\end{array}$ & $\begin{array}{l}812.533 \\
650.943 \\
712.866 \\
332.376 \\
219.709 \\
291.981\end{array}$ & $\begin{array}{r}217.452 \\
157.457 \\
207.927 \\
90.852 \\
25.088 \\
83.028\end{array}$ & $\begin{array}{c}313.619 \\
221.485 \\
193.765 \\
144.057 \\
49.753 \\
87.044\end{array}$ & $\begin{array}{r}1.882 .679 \\
1.378 .972 \\
1.474 .113 \\
763.355 \\
605.307 \\
707.769\end{array}$ \\
\hline \multicolumn{6}{|c|}{ b) anchoveta } \\
\hline $\begin{array}{l}1987 \\
1988 \\
1989 \\
1990 \\
1991 \\
1992\end{array}$ & $\begin{array}{r}16.460 \\
125.849 \\
460.624 \\
179.750 \\
330.629 \\
426.635\end{array}$ & $\begin{array}{r}68.421 \\
462.510 \\
572.819 \\
306.107 \\
186.161 \\
369.497\end{array}$ & $\begin{array}{r}35.439 \\
138.269 \\
137.615 \\
81.130 \\
47.239 \\
117.053\end{array}$ & $\begin{array}{r}84.386 \\
83.812 \\
166.369 \\
40.731 \\
41.156 \\
78.389\end{array}$ & $\begin{array}{r}204.706 \\
810.440 \\
1.337 .427 \\
607.718 \\
605.185 \\
991.574\end{array}$ \\
\hline
\end{tabular}

Fuente: SERNAP (1987-92) 
tografías mensuales muestra una clara tendencia a la disminución de la abundancia de sardina desde principios de 1989 (Fig. 10a). La recuperación de este índice entre fines de 1991 y principios de 1992 , se relacionaría con la distribución más costera del recurso producto del evento El Niño.

La componente estacional de la CPUE muestra que los mayores valores se presentan durante el primer trimestre, y entre el tercero y cuarto (Fig. 10b), asociados a los límites entre las estaciones cálida y fría (Fig. 1). Bajo condiciones ambientales normales la sardina presenta un desove prolongado entre julio y marzo, con una moda intensa en agosto-septiembre y otra de menor intensidad en febrero-marzo (Serra y Tsukayama, 1988). En 1991, el índice gonadosomático de sardina de la zona norte de Chile muestra valores máximos durante marzo, y nuevamente en agosto y septiembre (Martínez et al., 1992). No obstante, en condiciones ambientales extremas como aquellas asociadas a los fenómenos El Niño, se producen drásticas alteraciones en cuanto a la magnitud y época de los picos de desove (Martínez et al., 1985).

La ubicación de los CG de las cartografías men suales de CPUE de sardina muestra dos grupos (Fig. $11)$, los cuales en general se relacionan con la componente estacional de la TSM (Fig. 1). En efecto, durante la estación fría (mayo-octubre) los CG presentan una posición más oceánica y al norte de los $21^{\circ} \mathrm{S}$. No obstante, en 1987 los CG de esos meses se encuentran más cerca de la costa, y los de la estación fría de 1989 y 1990 relativamente más al sur. Durante la estación cálida (noviembre-abril) los CG se sitúan más cerca de la costa y al sur de los $20^{\circ} \mathrm{S}$, con la notable excepción de noviembre y diciembre de 1991.

Las cartografías mensuales de CPUE y sus respectivos CG muestran la distribución más costera del recurso durante 1987 (Figs. 9a y 11), lo cual se asocia a los efectos del evento El Niño ocurrido este año (Figs. 1 y 2). En efecto, después de enero la sardina tiende a distribuirse hacia el sur, cuando comienzan las fuertes anomalías de TSM. Luego el recurso amplía su repartición y se concentra al norte de los $21^{\circ} \mathrm{S}$ en invierno (junio-agosto); posteriormente recupera cobertura latitudinal y se concentra en el sur a fines de año, cuando en la zona se presentan importantes anomalías positivas de TSM.

En enero de 1988 el recurso se encuentra más bien concentrado en el sur, para enseguida tender hacia el norte, donde se ubica entre mayo y julio (Fig. 9a). Posteriormente, la distribución del recurso es más amplia en latitud y longitud, sobre todo a fines de año cuando la TSM es comparativamente más fría (Figs. 1 y $2 \mathrm{a}$ ).

En enero de 1989 la sardina presenta una amplia distribución centro-sur con un CG alejado de la costa (Figs. 9a y 11); en ésta la TSM es fría (Fig. 3a), particularmente en el centro-norte (Fig. 1). A partir de febrero la sardina marca nuevamente su preferencia por la parte centro-norte, sin llegar a concentrarse en el norte. El recurso recupera cobertura latitudinal a partir de julio, tiende hacia el sur en noviembre, donde se concentra en diciembre. La estructura térmica superficial del mar presenta entre enero y octubre condiciones medias bastante estables, en tanto que en noviembre y diciembre se presentan importantes anomalías positivas de TSM (Figs. 1 y 2 a).

En promedio el año 1990 es el más frío del período de estudio; sin embargo, en enero continúan presentándose altos valores de TSM (Fig. 2b), asociados a la concentración del recurso en el sur (Fig. 9b). Luego, cuando el mar comienza a enfriarse, el recurso tiende a desplazarse hacia el norte. Lo más significativo es que a fines de año la sardina se distribuye de preferencia en el norte, cuando las condiciones son comparativamente frías (Figs. 1 y 2).

Durante 1991 las variables ambientales presentan valores promedios anuales aparentemente normales; pero dentro del año tienden a aumentar, lo cual se asocia a los primeros efectos de El Niño (Figs. 2b, 3 b y 4). La escasa información de enero a julio dificulta el análisis de la distribución del recurso; es muy probable que después de enero las bajas capturas se lograron en el norte de la zona. Durante el segundo semestre los desembarques aumentan (Fig. 7a), y se lograron en su mayoría al norte y bastante alejados de la costa (Fig. 9b), lo que se refleja en la posición de los CG (Fig. 11). Esto estaría implicando una efectiva disminución de la abundancia y/o disponibilidad del recurso en la zona.

En 1992 se registran en la zona notables anoma lías de TSM asociadas al fenómeno El Niño (Figs. 1 y 2), sobre todo después de febrero en la costa (Fig. 3). El Niño habría producido un aumento de la disponibilidad del recurso, reflejado en el aumento de los desembarques entre fines de 1991 y principios de 1992 (Fig. 7a); lo mismo se constata al observar la distribución y magnitud de la CPUE (Figs. 9b y 10a). Lo notable es que las anomalías positivas de TSM 
no se asocian a concentraciones del recurso en el sur. En marzo, por ejemplo, estas anomalías se relacionan con la importante concentración del recurso en el norte.

\section{Variaciones espaciales y mensuales de la CPUE de anchoveta}

En las Figuras 12a y 12b se presenta la distribución espacial y mensual de la CPUE de ancho veta, destacándose la escasa o nula información de los meses afectados por las vedas extractivas, salvo aquellos favorecidos por la intensidad de los muestreos biológicos. También es poca la información de los meses durante los cuales la flota cerquera industrial logró bajas capturas (señalados con el signo ?). No obstante, se confirma que el recurso se distribuye de preferencia dentro de las primeras $60 \mathrm{mn}$ de la costa, registrándose al norte de los $21^{\circ} \mathrm{S}$ concentraciones más alejadas, sobrepasando en julio de 1989 los $72^{\circ} \mathrm{W}$.

Sin tomar en cuenta los meses más afectados por las vedas extractivas (enero, febrero, agosto y diciembre), la señal desestacionalizada de la CPUE promedio de las cartografías mensuales de anchoveta muestra una tendencia al aumento hasta fines de 1989, para luego disminuir y presentar una relativa estabilización al final del período de estudio (Fig. 13a). Los bajos niveles de 1987 se asocian a los efectos del evento El Niño, el cual produjo importantes anomalías de temperatura durante todo el año (Fig. 2). Además, en esta evolución sobresalen los altos valores CPUE de fines de 1990 y principios de 1991, período de temperaturas comparativamente frías, y de principios de 1992, cuando se dejan sentir fuertes anomalías positivas de temperatura producto del fenómeno El Niño.

En relación con la componente estacional de la CPUE, los mayores valores se lograrían durante el primer trimestre asociados al proceso de reclutamiento (Fig. 13b), el cual se protege con las vedas extractivas de fines y principios de año (Tabla 2). El aumento de la CPUE que se observa después de junio, se relaciona con la principal época de desove que se desarrolla durante el segundo semestre. En 1991, por ejemplo, la anchoveta empezó a desovar en julio, observándose la máxima actividad reproductiva en agosto, terminando el ciclo a comienzos de 1992 (Martínez et al., 1992).

Durante 1987, asociadas a los efectos del fenómeno El Niño y a los mayores desembarques de sardina (Tabla 6a), las capturas totales de anchoveta fueron las más bajas del período (Tabla 6b). Estas se realizaron principalmente a principios de año (Fig. 8a), y mayormente al sur y cerca de la costa (Fig. 12a y 14).

En 1988 la estructura térmica superficial presentó condiciones normalizadas, aunque comparativamente más fría a fines de año (Fig. 1). Durante los meses cálidos de principios de año la anchoveta se habría distribuido de preferencia en la parte centrosur y en invierno (junio-septiembre) en la parte centro-norte; mientras que hacia fines de año, en ellímite de las estaciones fría y cálida (octubre- noviembre), el recurso presentó la mayor cobertura latitudi nal(Fig. 12a y 14).

Durante 1989, de condiciones térmicas normales salvo al final (Fig. 2), el recurso registra los desembarques más importantes del período (Tabla 6b). Este se encuentra a lo largo de la costa, pero más concentrado en la parte centro-sur hasta abril; luego, sin dejar la parte central, se distribuye de preferencia en el norte, volviendo a registrarse en el sur a fines de año (Fig. 12a).

Después de 1989 los desembarques totales de anchoveta decrecen; no obstante, en 1991 y 1992 éstos son más importantes en el puerto de Arica (Tabla 6b). En 1992 las capturas se recuperan, lo cual se asocia a efectos de concentración producidos por el evento El Niño.

En 1990, de condiciones frías a partir de febrero y sobre todo a fines de año (Fig. 1 y 2), la anchoveta se encuentra a lo largo de toda la costa hasta mayo; posteriormente, y en particular durante el cuarto trimestre, muestra una clara preferencia por la parte centro-norte (Figs 12b y 14). A juzgar por la posición de los CG, esta preferencia por la parte centro norte se mantendría durante 1991 y 1992, aunque algunas observaciones son registradas en el sur.

\section{Consideraciones generales}

Se confirma que la anchoveta se distribuye de preferencia dentro de las primeras $60 \mathrm{mn}$ de la costa, aunque en ocasiones sobrepasa este límite en el norte de la zona de estudio (Figs. 12a y 12b). En efecto, los valores más importantes de CPUE se ubican dentro de las primeras $20 \mathrm{mn}$ de la costa y estrechamente asociados a los focos permanentes de surgencia. Estos se localizan al sur de Arica, al norte y sur de Iquique, al sur del río Loa y alrededor de Mejillones (Barbieri et al., 1995), donde se registran las mayo- 
res concentraciones de clorofila «a» (Osses. 1990). Las distribuciones más amplias que se observan en el norte en julio de 1989. y octubre. noviembre y diciembre de 1990. se asociarían a meses comparativamente más fríos (Fig. 1). Sin embargo. las distribuciones similares observadas en marzo-mayo de 1992. se asocian a condiciones cálidas relacionadas con el fenómeno El Niño.

La sardina presenta una distribución más amplia en la zona y. en relación con la anchoveta. más alejada de la costa (Figs. 9a y 9b). Esto se deduce de la ubicación de los centros de gravedad de las distribuciones mensuales de CPUE de ambas especies. los cuales normalmente no se sobreponen (Figs. $11 \mathrm{y}$ 14). La anchoveta aprovecharía la cantidad y calidad de alimentos derivados de los primeros efectos de las surgencias. las cuales se extienden hasta las 30-40 ron de la costa a principios de año (enero-abril) y hasta las 20-25 ron en invierno Gunio-septiembre) (Barbieri et al. 1995). La sardina. más alejada de la costa. esperaría un cierto grado de maduración de los efectos de las surgencias y en la zona más oceánica aprovecharía el enriquecllniento biológico que produce el aporte de nutrientes inorgánicos de altas latitudes. Además. cabe señalar que la sardina es un importante depredador de huevos de anchoveta (Santander et al., 1983).

La distribución espacio-temporal de sardina presenta variaciones que se asocian a modificaciones de la estructura térmica superficial del mar. las cuales se pueden generalizar del siguiente modo: a) durante meses cálidos de principios y fines de año (diciembre-marzo). con características de fenómenos El Niño. la sardina se concentra en el sur (Fig. 15a); salvo en marzo de 1992. cuando las notables anomalías positivas de TSM la concentraron en el norte; b) al disminuir dicho tipo de calentamiento se distribuye a lo largo de la costa. ubicándose cerca de las áreas de surgencia (Fig. 15b); c) durante los meses fríos se encuentra de preferencia en el norte (Fig. 15c); y d) las distribuciones más amplias en latitud y longitud se observan hacia fines de año. entre las estaciones fría y cálida (Fig. 15d); aunque en ocasiones este tipo de distribución también se observa en invierno.

La distribución de anchoveta también presenta variaciones asociadas a los cambios espacio-temporales de la TSM. que se pueden resumir de la siguiente forma: a) durante meses muy cálidos tendería a distribuirse en el centro-sur y cerca de la costa
(Fig. 16a); aunque en marzo y abril de 1992, de condiciones excepcionalmente cálidas, se presentaron importantes concentraciones en el centro-norte; b) en condiciones más frías se distribuye a lo largo de la costa y muy cerca de las áreas de surgencia (Fig. $16 b)$; c) en la estación fría se ubica de preferencia en el centro-norte (Fig. 16c); y d) las distribuciones más amplias se observan hacia fines de año. particularmente durante meses de anomalías negativas de TSM (Fig. 16d); no obstante. lo mismo ocurre en julio de 1989.

Se deduce que el fenómeno El Niño de 1992. que en la zona de estudio se deja sentir con gran intensidad a partir de marzo (Figs. 2 y 3). afectó de forma distinta la distribución de ambos recursos. Este, a diferencia de El Niño de 1987. produjo significativos grados de concentración en la parte norte durante los primeros meses más cálidos (Fig. 9b y 12b). Esto se asocia a la llegada más tardía y más violenta cerca de la costa de dicho fenómeno, limitando el desplazamiento de los recursos hacia el sur. También se relaciona con la tendencia general de ambos recursos por distribuirse cada vez más al norte, desde el comienzo de las condiciones frías de 1990 (Figs. 11 y 14). En el caso de la sardina. esta tendencia se asocia con la disminución de su abundancia durante los últimos años del período de estudio.

\section{CONCLUSIONES}

Normalmente en evaluación de recursos pesqueros se trabaja con modelos que consideran la evolución en el tiempo de variables biológico-pesqueras y, más recientemente, de condiciones ambientales asociadas. En este trabajo la aplicación de un SIG resultó de gran relevancia al integrar formalmente el análisis de variaciones espacio-temporaIes de ese tipo de variables, lo cual es de gran importancia en recursos pelágicos, dado que sus distribuciones y abundancias se ven afectadas por las fluctuaciones que en el tiempo y el espacio presenta el medio ambiente.

El estudio implicó el análisis de la TSMM obtenida de imágenes satelitales, para solucionar en gran medida el problema de la interferencia de las nubes, resultando un buen indicador de las variaciones espacio-temporales de la estructura térmica superficial del mar. En efecto, en las imágenes de TSMM del período 1987-92 se la marcada señal anual, con una estación cálida entre noviembre y abril, en tanto que 
entre julio y septiembre se registran las temperaturas más bajas.

También se constató que el evento El Niño de 1987 produjo en la zona importantes anomalías positivas de TSM y del NM; lo mismo implicó El Niño de 1992, pero en forma más marcada a principios de año cerca de la costa. Los meses de noviembre y diciembre de 1989, y de enero de 1990 , resultan también particularmente cálidos. Sin embargo, durante el resto de los meses de 1990 se producen en la zona las anomalías negativas de TSM más importantes del período 1987-92.

El análisis de las distribuciones espaciales e interanuales de CPUE de sardina y anchoveta indica diferencias significativas entre ambas especies. La anchoveta se distribuye de preferencia dentro de las primeras $60 \mathrm{mn}$ de la costa, mientras que la sardina presenta una distribución más amplia al alcanzar los $73^{\circ} \mathrm{W}$. Al comparar las distribuciones anuales de CPUE de sardina se establecen diferencias entre sí; lo mismo sucede al comparar entre sí las cartografías anuales de CPUE de anchoveta. Estas diferencias se asocian a variaciones de la abundancia de los recursos y a los efectos de las modificaciones de la estructura térmica superficial del mar. Durante los eventos El Niño de 1987 y 1992, ambas especies presentan distribuciones más costeras y en los últimos años del período de estudio se producen en la zona notables disminuciones de abundancia, particularmente de sardina.

Las distribuciones espaciales y mensuales de sardina y anchoveta presentan variaciones que se asocian a las modificaciones de la estructura térmica superficial del mar. Estas se pueden generalizar del siguiente modo: a) durante meses cálidos de principios y fines de año, con características de fenómenos El Niño, los recursos tienden a distribuirse en el sur; b) en condiciones normales, hasta fines de la estación cálida éstos se encuentran prácticamente a lo largo y cerca de la costa; c) en la estación fría los recursos se distribuyen de preferencia en el norte; y d) las distribuciones más amplias en latitud y longitud se observan hacia fines de año. No obstante, durante los meses comparativamente más fríos de fines de 1990 los recursos continúan de preferencia distribuidos en el norte. Por otra parte, el Niño de 1992 afectó de forma distinta la distribución de ambos recursos, al producir importantes grados de concentración en el norte durante los meses más cálidos de principios de año.

\section{AGRADECIMIENTOS}

Agradecemos muy sinceramente a la Empresa Pesquera IGEMAR S.A., y particularmente al Ing. Pesq. Guido Drago, por facilitar gran parte de la información satelital y pesquera analizada en el presente trabajo. De la misma manera se agradece al Servicio Hidrográfico y Oceanográfico de la Armada y al Servicio Meteorológico de Chile, por proporcionar los datos de las estaciones de mareógrafos y meteorológicas de la zona de estudio. En forma particular reconocemos la colaboración del Ing. Martín Farías, actualmente integrado al Programa de Percepción Remota y SIG de la Pontificia Universidad Católica de Chile. Finalmente, agradecemos las valiosas sugerencias de los revisores del trabajo.

\section{REFERENCIAS BIBLIOGRAFICAS}

Bakun, A. y R.H. Parrish. 1982. Turbulence, transport and pelagic fish in the California and Perú current systems. Calif. Coop. Oceanic Fish. Invest., Rep. 23: 99-112.

Barbieri, M.A. 1991. The use of remote sensors in fisheries. Euro-Latin American Space Days, 25 29 noviembre, Rio de Janeiro, Brasil, 6 pp.

Barbieri, M.A., F. Naranjo, E. Yáñez, M. Farías, G. Daneri y P. Rojas. 1987. La pesquería artesanal de atún aleta larga (Thunnus alalunga) en la zona de Valparaíso $\left(33^{\circ} \mathrm{S}-72^{\circ} \mathrm{W}\right)$ y el satélite NOAA. Invest. Mar., Valparaíso, 15: 41-61.

Barbieri, M.A., E. Yáñez y M. Farías. 1989a. Efecto del fenómeno El Niño 1987 en la pesquería artesanal de atún aleta larga (Thunnus alalunga) en la zona de Valparaíso, Chile. Pacífico Sur, Número Especial: 521-527.

Barbieri, M.A., E. Yáñez, M. Farías y R. Aguilera. 1989b. Determination of probable fishing areas for the albacore (Thunnus alalunga) in Chile's central zone. In: «Quantitative Remote Sensing», IGARSS '89, Vancouver-Canadá, Vol. 4: 24472450 .

Barbieri, M.A., E. Yáñez y M. Farías. 1991. La télédétection et la pêche artisanale du germon et de l'espadon au Chili: un cas de transfert de technologie. In: «La Recherche Face à la Pêche Artisanale», J.R. Durand, J. Lemoalle et J. Weber (Eds.), ORSTOM, París, Tome II: 817-824. 
Barbieri, M.A., M. Bravo, M. Farías, A. González, O. Pizarro y E. Yáñez. 1995. Fenómenos asociados a la estructura térmica superficial del mar observados a través de imágenes satelitales en la zona norte de Chile. Invest. Mar., Valparaíso, Vol. 23: 99-122.

Bernal, P. 1990. La oceanografía del sistema de corrientes de Chile-Perú en relación a las pesquerías pelágicas: Una revisión. In: «Perspectivas de la Actividad Pesquera en Chile», M.A. Barbieri (Ed.), Escuela de Ciencias del Mar, UCV, Valparaíso: 3548.

Bemal, P., F. Robles y O. Rojas. 1983. Variabilidad física y biológica en la región meridional del sistema de corrientes Chile-Perú. FAO Fish. Rep., (291) Vol. 3: 683-711.

Bravo, M. 1993. Estudio de los procesos de surgencia costera en el norte de Chile entre 1989 y 1990 (Arica-Antofagasta). Tesis, Escuela de Ciencias del Mar, UCV, 115 pp.

Cañón, J.R. 1978. Distribución de la anchoveta (Engraulis ringens) en el norte de Chile en relación a determinadas condiciones oceanográficas. Serie Invest. Pesq., IFOP (Chile), 30: 1-122.

Cañón, J.R. 1986. Variabilidad ambiental en relación con la pesquería pelágica de la zona norte de Chile. In: «La Pesca en Chile», P. Arana (Ed.), Escuela de Ciencias del Mar, UCV, Valparaíso: 195 205.

Cañón, J.R. 1990a. Regulaciones pesqueras aplicadas al recurso anchoveta en Chile. Chile Pesquero, 58: 41-45.

Cañón, J.R. 1990b. Regulaciones pesqueras aplicadas al recurso sardina española en Chile. Chile Pesquero, 59: 35-41.

Castillo, J. y O. Guzmán. 1985. Variaciones de la distribución espacial de la sardina española y jurel durante El Niño 1982-83. Invest. Pesq. (Chile), 32 : 79-93.

Castillo, J., M.A. Barbieri y A. González. 1995. Relationships between sea surface temperature, salinity and the pelagic fish distribution off nortbem Chile. ICES, Inter. Symp. on Fisheries and Plankton Acoustics, Paper $\mathrm{N}^{\circ} 157,13$ pp. (en prensa).
Chirichigno, N., W. Fischer y C.E. Naveo. 1982. Catálogo de especies marinas de interés económico actual o potencial para América Latina. Parte 2. Pacífico Centro y Suroriental. FAO-PNUD, SIC 82-2, $588 \mathrm{pp}$.

Comisión Permanente del Pacífico Sur (CPPS). 1993. Seminario Taller y Consulta de Expertos sobre Recursos Pelágicos y sus Pesquerías en el Pacífico Sudeste: Una reflexión al Futuro. CPPSFAO-PNUD, Buenaventura-Colombia, Informe Final, 72 pp.

Csirke, J. y G.D. Sharp (Eds.). 1984. Reports of the expert consultation to examine changes in abundance and species composition of neritic fish resources. FAO Fish. Rep., (291) Vol. 1: 1104.

Cubillos, L. y R. Fuenzalida. 1990. El período cálido de 1976 a 1984 y sus efectos en los desembarques de algunos peces de importancia comercial de la zona norte de Chile. Cienc. y Tec. del Mar, CONA (Chile), 14: 3-19.

De Buen, F. 1960. La sardina y sardina española (Sardinops sagax) en la costa sur de América del Océano Pacífico (Chile-Perú e Islas Galápagos). FAO Fish. Biol. Synop., 13.

Eastman, J.R. 1992. IDRISIVersion 4.0, User's Guide. Clark University Graduate School of Geography, USA, 178 pp.

Laurs, M. 1989. Review of satellite application lo fisheries. In: "Quanlilative Remole Sensing, IGARSS '89", Vancouver-Canada, 4: 2037-2040.

Le GaII, J.Y. (Ed.). 1989. Télédétection atellitaire et pêcheries thonière océanique. FAO Doc. Tech. Pêches,302: 1-148.

Mann, K.H. 1992. Physical infIuences on biological processes: how important are they ? S. Afr. J. mar. Sci.,12: 107-121.

Martínez, C., L. Caballero, G. Böhm, J. Oliva, R. Gili, V. Bocie, P. Barría y R. Serra. 1992. Diagnóstico de las principales pesquerías nacionales: pesquerías pelágicas zona norte. CORFO-IFOP, Chile, SGI-IFOP 92/1, 51 pp.

Martínez, C., C. SaIazar, G. Böhm, J. Mendieta y C. Estrada. 1985. Efectos del fenómeno El Niño 1982-83 sobre los principales recursos pelágicos y su pesquería (Arica-Antofagasta). Invest. Pesq. (Chile), 32: 129-139. 
Osses, J. 1990. Clorofila «a» y variables oceanográficas en el norte de Chile. Chile Pesquero, 58: 28-29.

Ott, L., R.F. Larson y W. Mendenball. 1983. Statistics: A tool for the Social Sciences, Boston: Duxbury Press.

Parrisb, R.H., R. Serra y W.S. Grant. 1989. The monotypic sardines, Sardina and Sardinops: their taxonomy, stock structure, and zoogeography. Can. J. Fish. Aquat. Sci., 46: 2019-2036.

Pauly, D. y I. Tsukayama. 1987. On the implementation of management oriented fishery research: the case of the peruvian ancho veta. In: «The Peruvian ancboveta and its upwelling ecosystem: three decades of changes», D. Pauly and I. Tsukayama (Eds.), ICLARM Studies and Reviews 15: 1-13.

Pettigiani, E., H. Karszenbaum y M. Mejail. 1992. Análisis de imágenes satelitarias de temperaturas superficiales mediante funciones empíricas ortogonales en la zona común de pesca argentinouruguaya. Revista SELPER, 8(1): 43-48.

Philander, S.G. 1990. El Nifío, La Nifía, and the Southern Oscillation. Inter. Geophysics Ser., Academic Press Inc.,46: 1-293.

Pizarro, O., S. Hormazabal, A. González y E. y Yáñez. 1994. Variabilidad del viento, nivel del mar y temperatura en la costa norte de Chile. Invest. Mar., Valparaíso, 22: 85-101.

Santander, H., J. Alheit, A.D. MacCall y A. Alamo. 1983. Egg mortality of the peruvian anchovy Engraulis ringens) caused by cannibalism and predation by sardines (Sardinops sagax). FAO Inf. Pesca, (291) Vol. 3: 1011-1025.

SERNAP. 1987-92. Anuarios Estadísticos de Pesca. Servicio Nacional de Pesca, Chile.

Serra, R. 1983. Changes in the abundance of pelagic resources along the chilean coast. FAO Fish. Rep., (291) Vol. 2: 255-284.

Serra, R. 1986. Desarrollo de la pesquería de anchoveta (Engraulis ringens) y los cambios de su abundancia. Invest. Pesq. (Chile), 33: 13-24.

Serra, R., M. Aguayo, O. Rojas, J. Cañón y F. Inostroza. 1979. Anchoveta Engraulis ringens (Jenyns) Teleostomi Clupeiformes Engraulidae. In: «Estado actual de las principales pesquerías nacionales. Bases para un desarrollo pesquero: I Peces». CORFO-IFOP (AP-79/18), 52 pp.

Serra, R. y I. Tsukayama. 1988. Sinopsis de datos biológicos y pesqueros de la sardina Sardinops sagax (Jenyns, 1842) en el Pacífico Suroriental. FAO Sinop. Pesca, (13) Rev. 1,60 pp.

White, W. y A.E. Walker. 1974. Time and depth scales of anomalous subsurface temperatures of Ocean Weather Stations P, N and V in the North PacifiCo Geophys. Res. W 79: 4517 -4522.

Yáñez, E. 1989. Fluctuaciones de los principales recursos pelágicos explotados en la zona norte de Chile y variaciones ambientales asociadas. Pacífico Sur, Número Especial: 509-520.

Yáñez, E. 1991. Relationships between environmental changes and fluctuating major pelagic resources exploited in Chile (1950-1988). In: «Long-term variability of pelagic fish populations and their environment», T. Kawasaki, S. Tanaka, Y. Toba and A. Tanigushi (Eds.), Pergamon Press: 301-309.

Yáñez, E. y M.A. Barbieri. 1986. Principal pelagic resources exploited in northem Chile and their relationships to environmental variations. In: «Long term changes marine fish populations», T. Wyatt and M.G. Larrañeta (Eds.), Vigo (España): 197-219.

Yáñez, E., M.A. Barbieri y O. Barra. 1986. Evaluación de los principales recursos pelágicos explotados en la zona norte de Chile entre 1957 y 1985. In: «La Pesca en Chile», P. Arana (Ed.), Escuela de Ciencias del Mar, UCV, Valparaíso: 183-194.

Yáñez, E., M.A. Barbieri, A. González, O. Pizarro, M. Bravo, C. Canales y S. Salinas. 1994. Sea surface structure associated to the pelagic fish resources distribution in northern Chile. In: «Remote Sensing for Marine and Coastal Environments», ERIM, Michigan, Vol. 11: 149162.

Yáñez, E., C. Canales, M.A. Barbieri, A. González y V. Catasti. 1993. Estandarización del esfuerzo de pesca y distribución espacial e interanual de la CPUE de anchoveta y de sardina en la zona norte de Chile entre 1987 y 1992. Invest. Mar., Valparaíso, 21: 111-132.

Recibido el 12 de abril de 1994.

Aceptado el 14 de septiembre de 1995. 


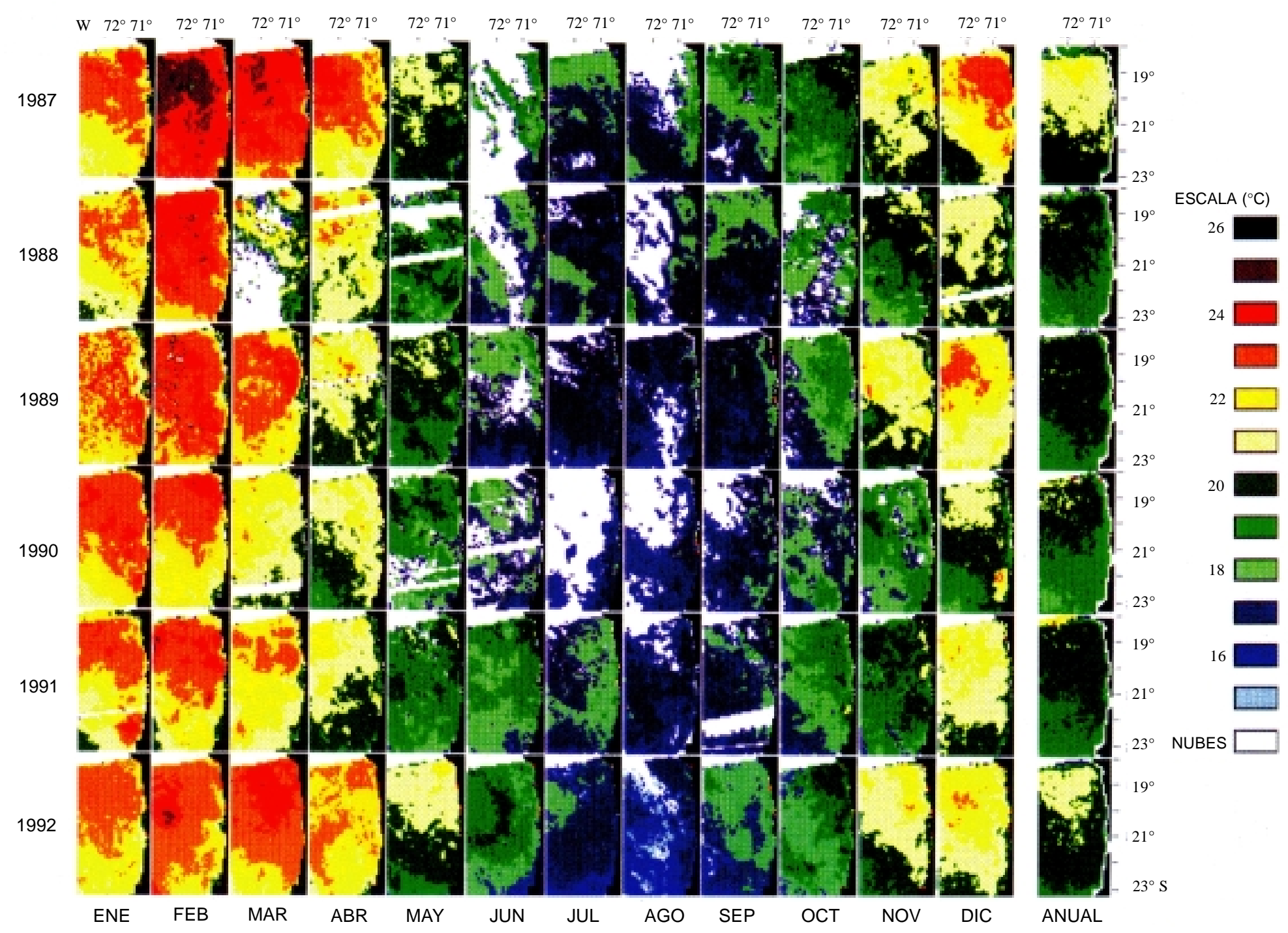

Figura 1. Distribución mensual y anual de TSMM en la zona norte de Chile $\left(18^{\circ} 21^{\prime}-24^{\circ} \mathrm{S}\right.$; de la costa a los $\left.73^{\circ} \mathrm{W}\right)$, estimada a partir de datos satelitales (1987-92). 


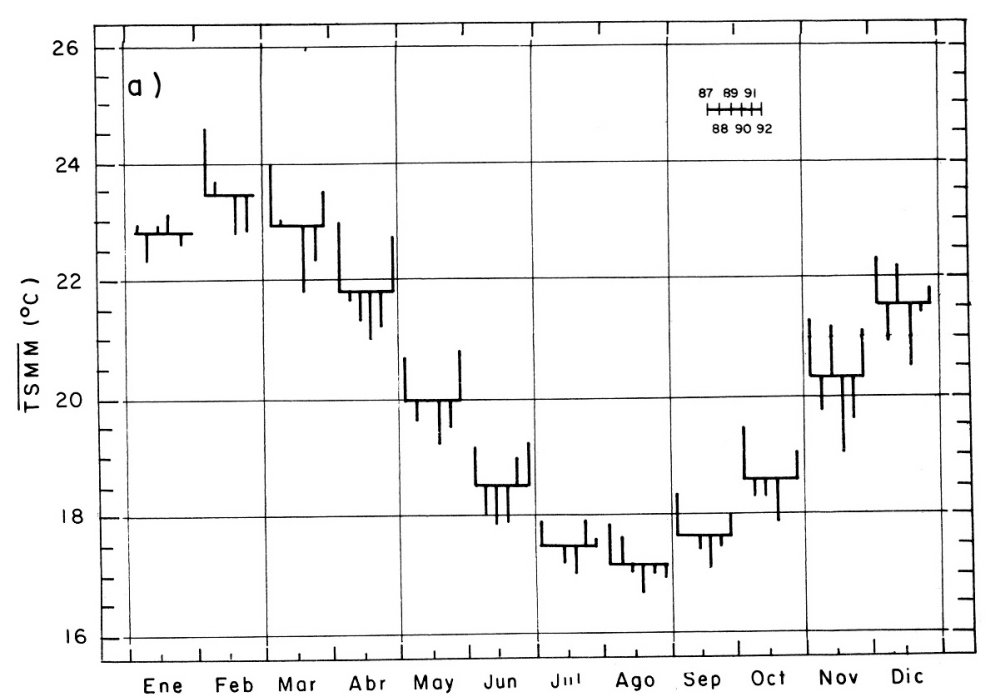

MES

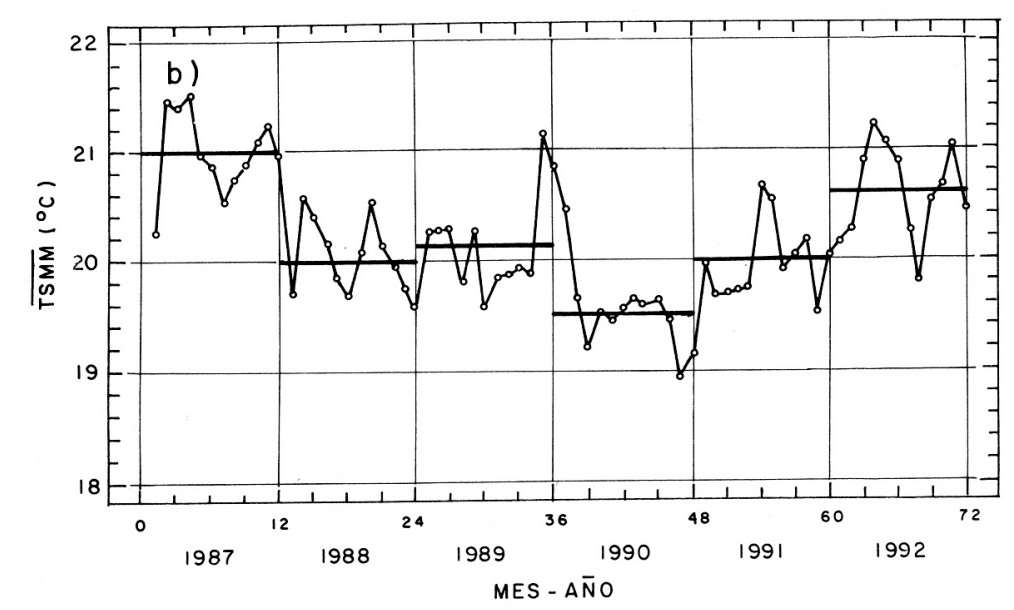

Figura 2. TSMM promedio en la zona norte de Chile, estimada a partir de datos satelitales (1987-92): a) señal anual y promedios mensuales, $y$ b) serie mensual desestacionalizada (modelo aditivo) y promedios anuales.
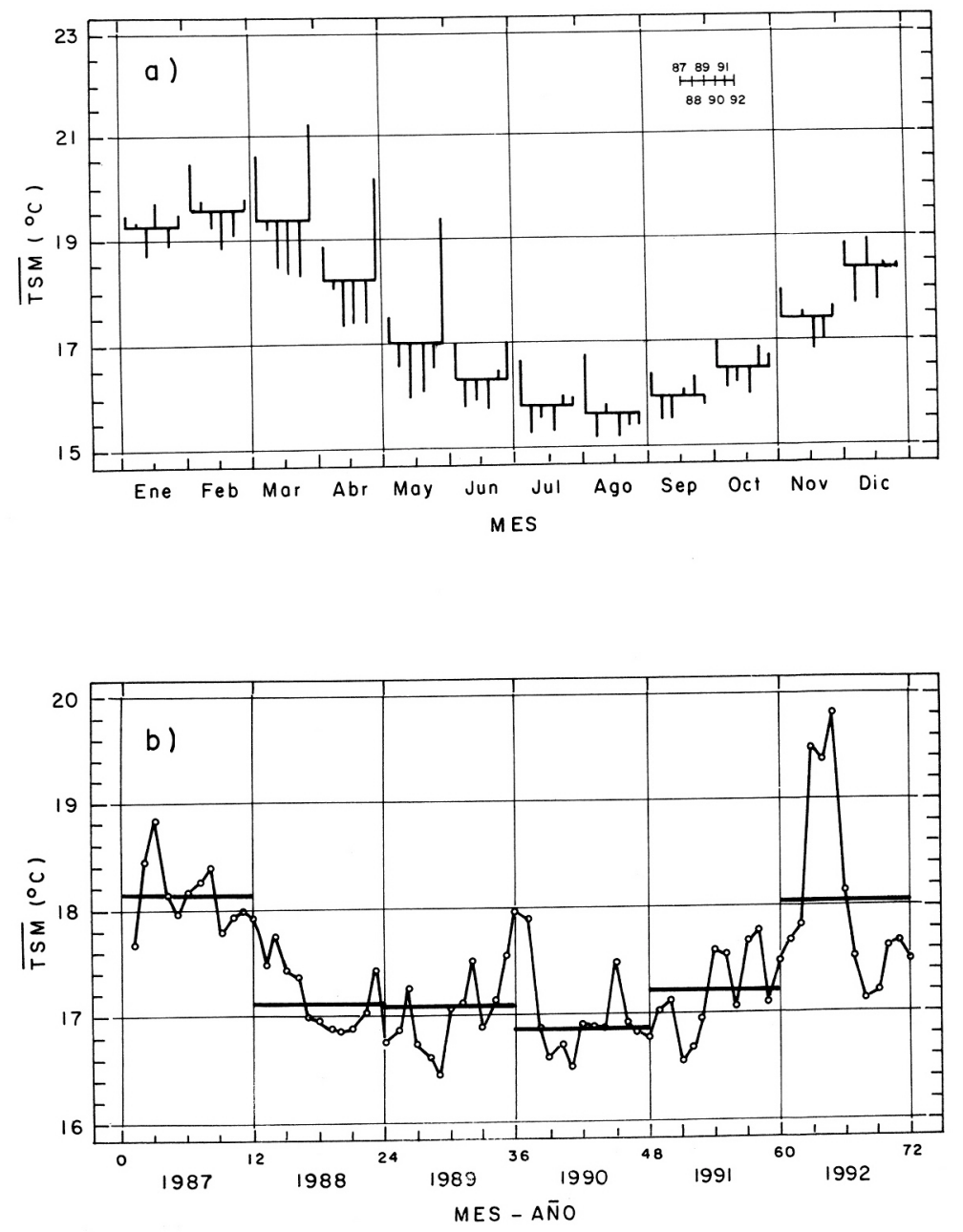

Figura 3. TSM promedio en las estaciones de mareógrafos de Arica, Iquique y Antofagasta (1987-92): a) señal anual y promedios mensuales, y b) serie mensual desestacionalizada (modelo aditivo) y promedios anuales. 


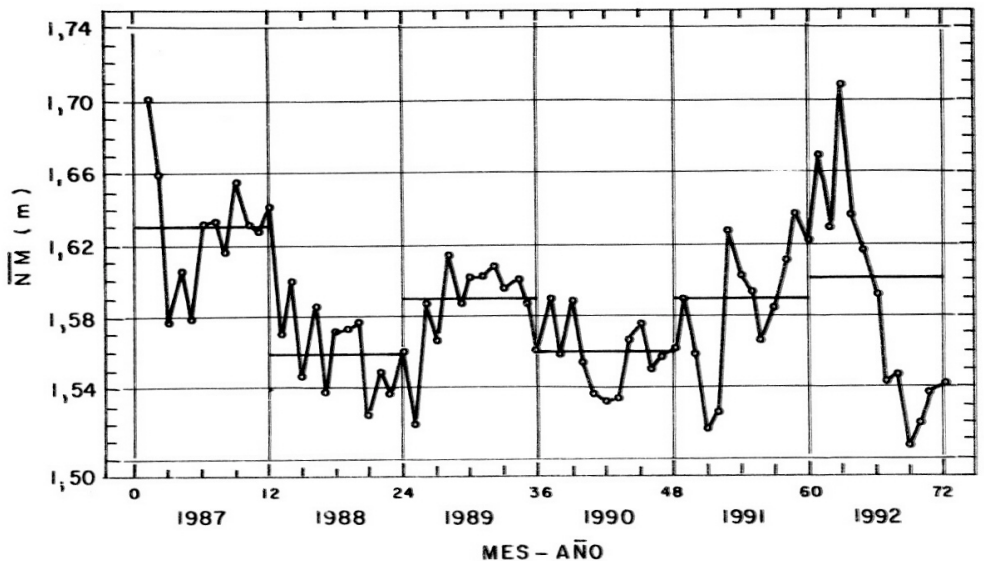

Figura 4. Serie mensual desestacionalizada (modelo aditivo) y promedios anuales del nivel del mar en la estación de mareógrafo de Arica (1987-92).

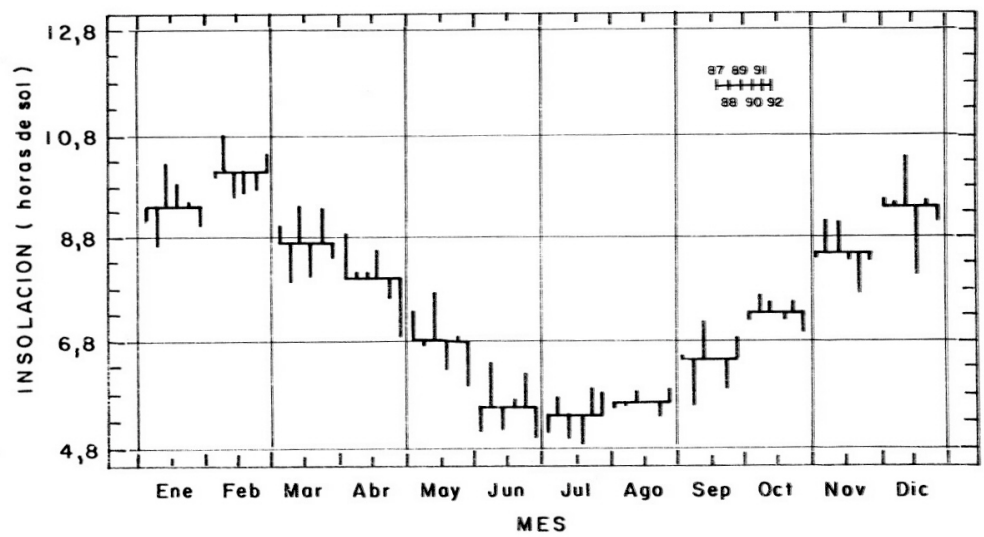

Figura 5. Señal anual y promedios mensuales de la insolación en las estaciones meteorológicas de Arica, Iquique y Antofagasta (1987-92).

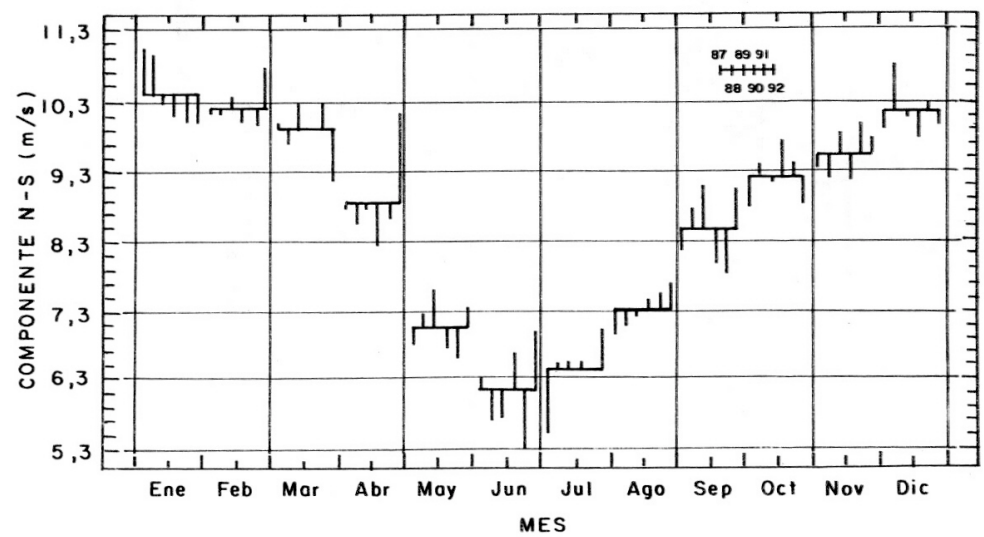

Figura 6. Señal anual y promedios mensuales de la componente $\mathrm{N}-\mathrm{S}$ del viento en las estaciones meteorológicas de Arica, Iquique y Antofagasta (1987-92). 

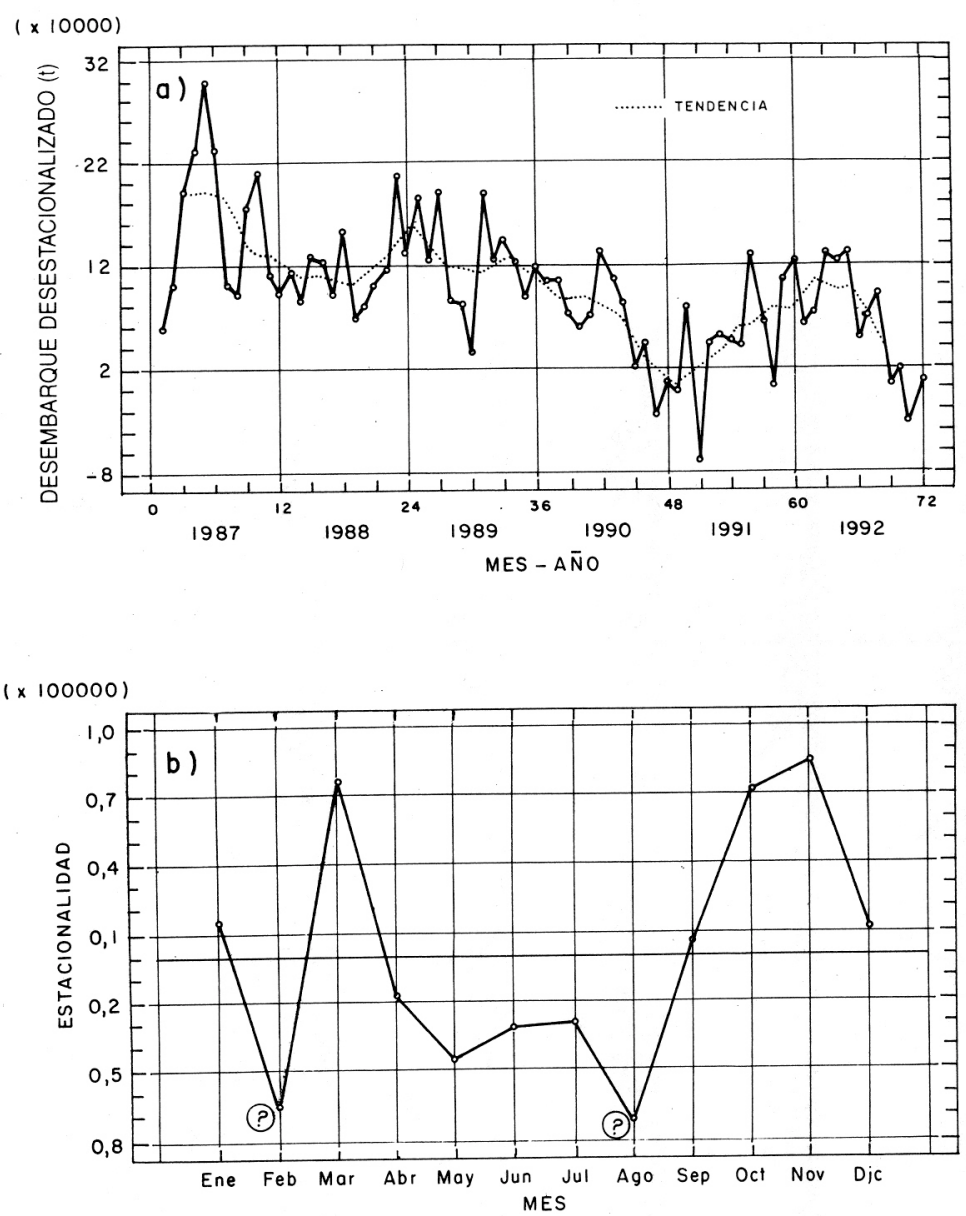

Figura 7. Desembarques mensuales de sardina en la zona norte de Chile (1987-92): a) señal desestacionalizada y tendencia, y b) componente estacional (modelo aditivo). El signo? indica meses en vedas extractivas.
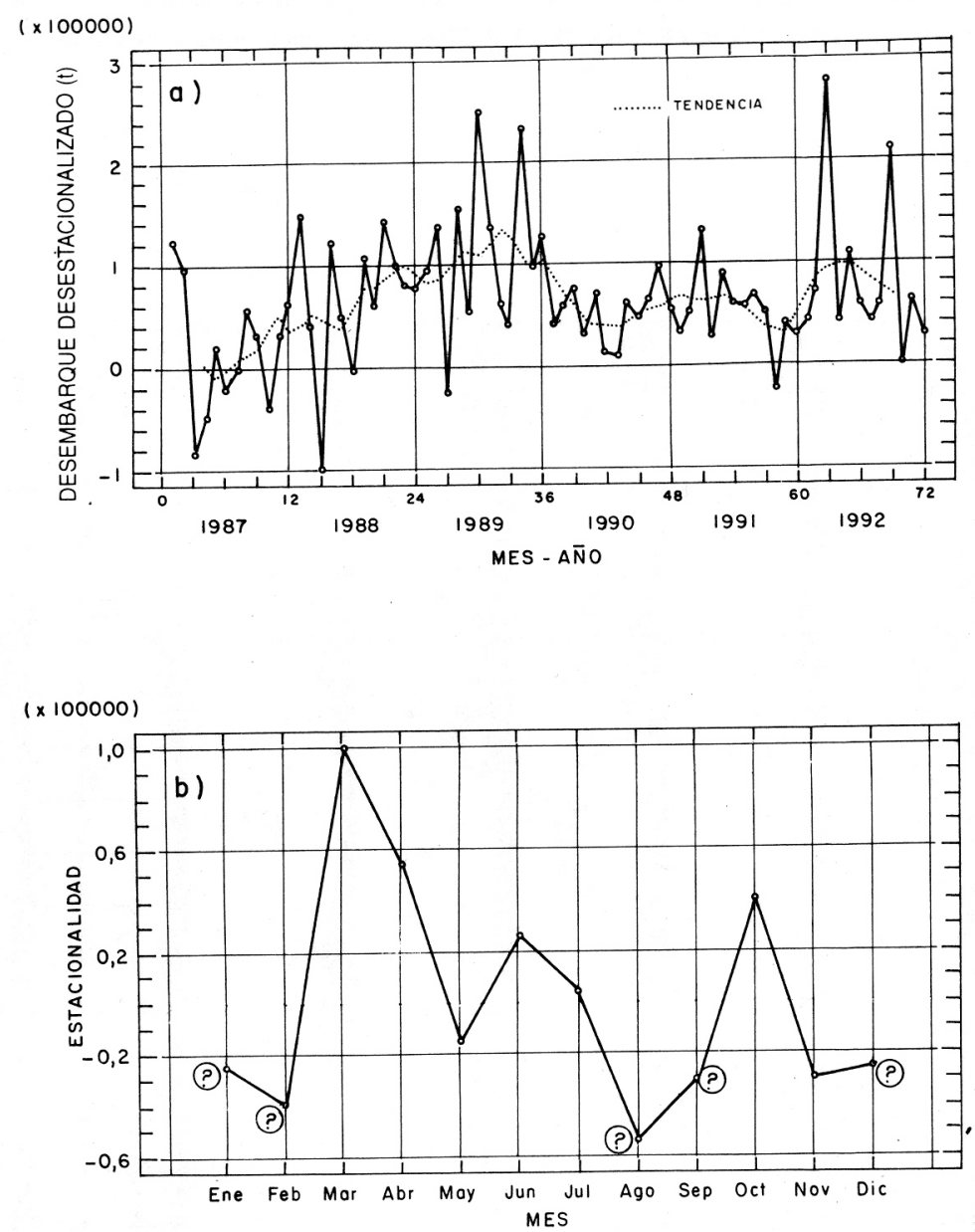

Figura 8. Desembarques mensuales de anchoveta en la zona norte de Chile 1987-92): a) señal desestacionalizada y tendencia, y b) componente estacional (modelo aditivo). El signo? indica meses en vedas extractivas. 


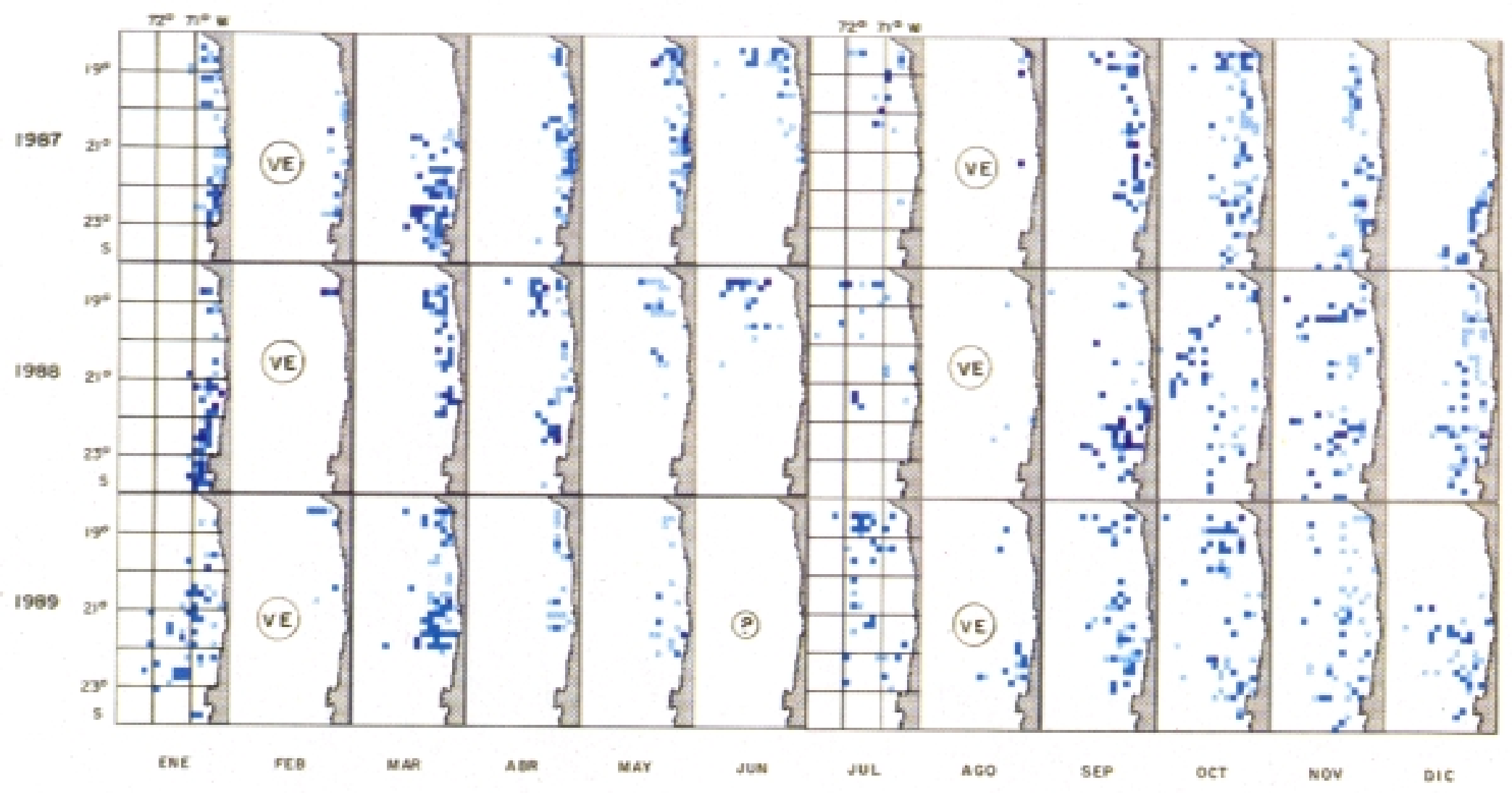

Figura 9a. Distribución espacial y mensual de la CPUE (t/dpe) de sardina en la zona norte de Chile: 1987-89. Categorías: a = 0,1-49,9; $b=50-99,9 ; c=100$ 149,9; y d $\geq 150$ (desde celeste claro a azul intenso). La sigla VE indica meses en vedas extractivas y el signo? un mes con captura total inferior a $3.500 \mathrm{t}$ (SERNAP, 1989). 


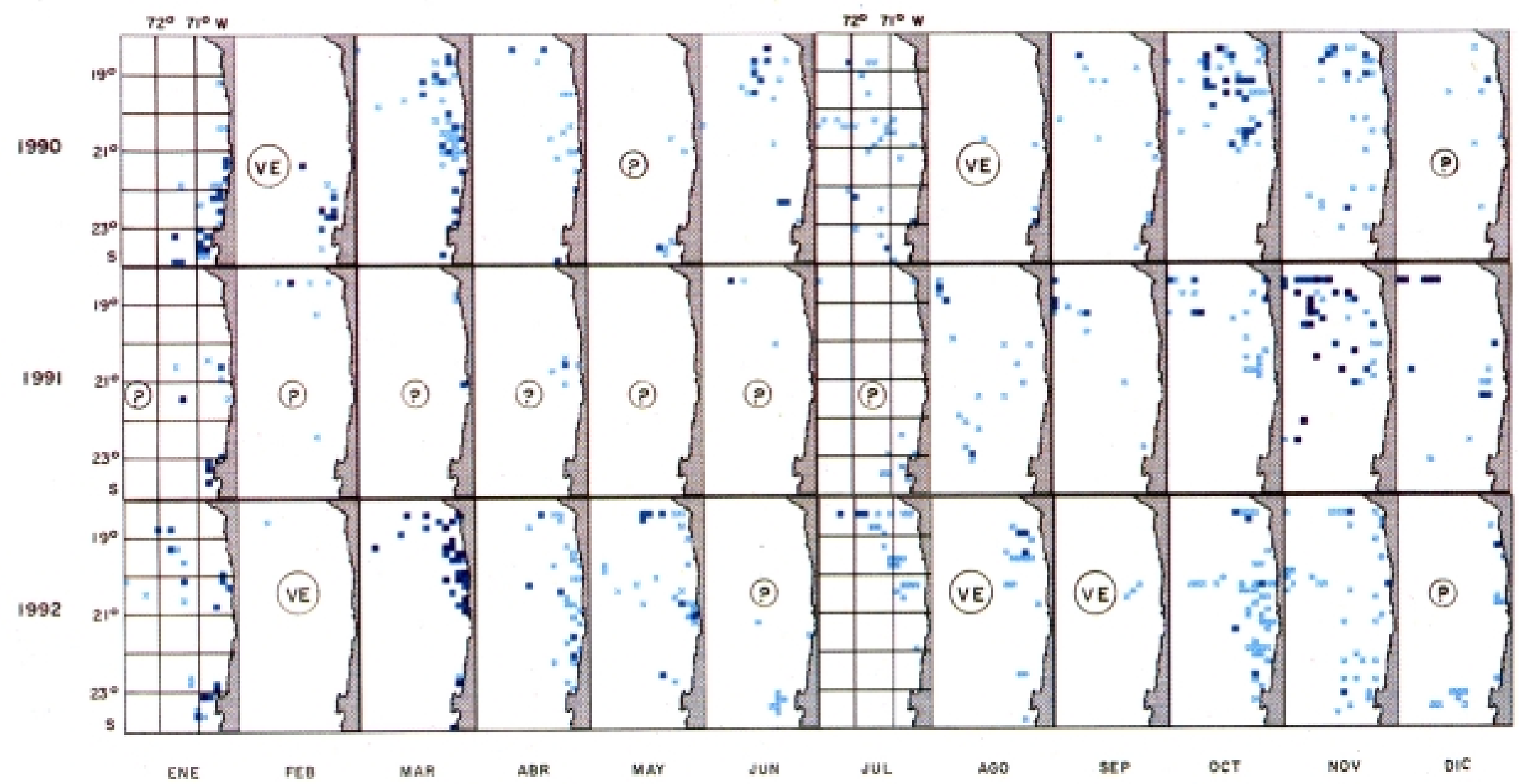

Figura 9b. Distribución espacial y mensual de la CPUE (t/dpe) de sardina en la zona norte de Chile: 1990-92. Categorías: a = 0,1-49,9; b = 50-99,9; $\mathrm{c}=$ 100149,9; y d $\geq 150$ (desde celeste claro a azul intenso). La sigla VE indica meses en vedas extractivas y el signo? meses con captura total inferior a 25.000 t (SERNAP, 1990-92). 

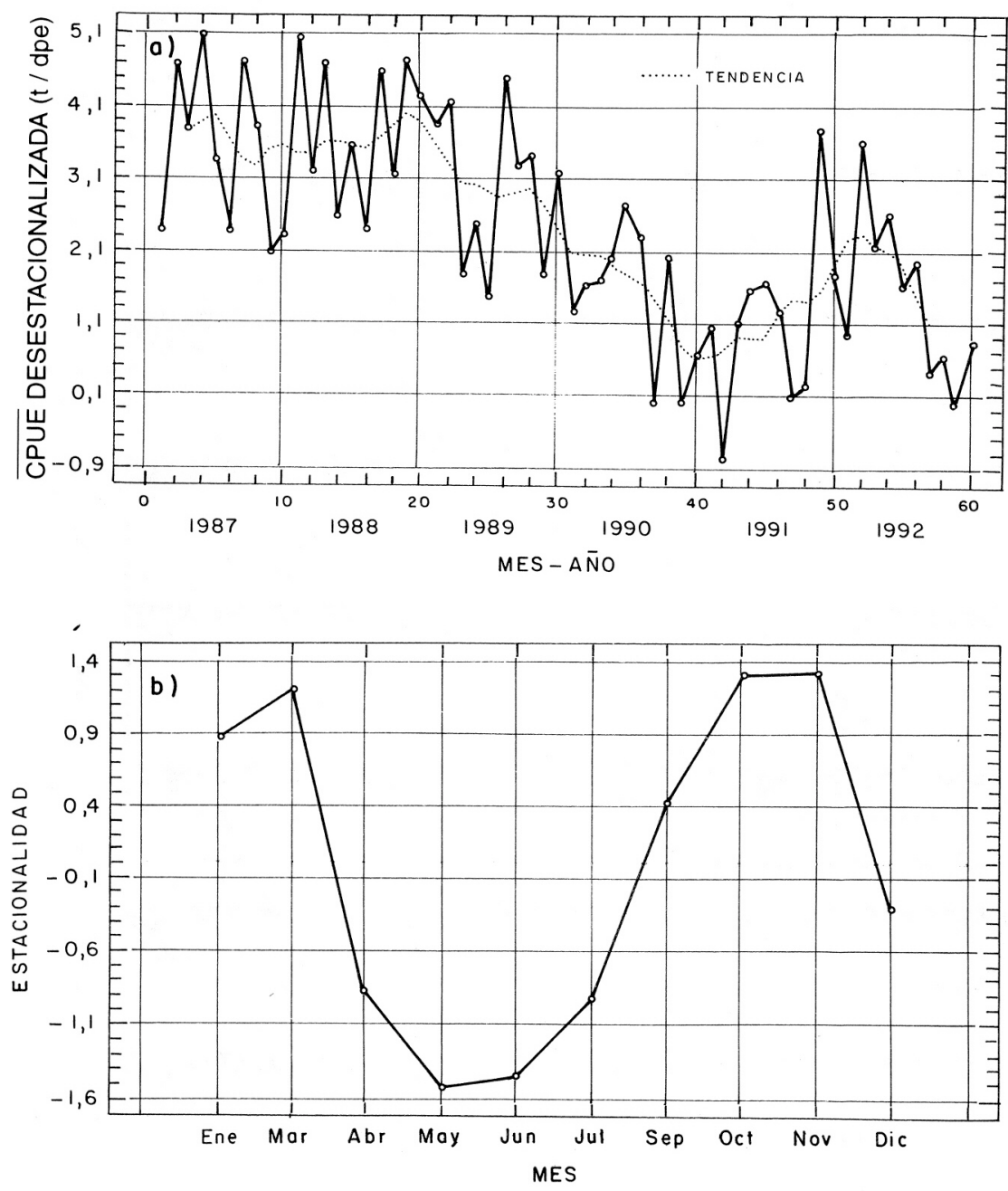

Figura 10. Promedios de las cartografías mensuales de CPUE de sardina (1987-92): a) señal desestacionalizada y tendencia, y b) componente estacional (modelo aditivo).

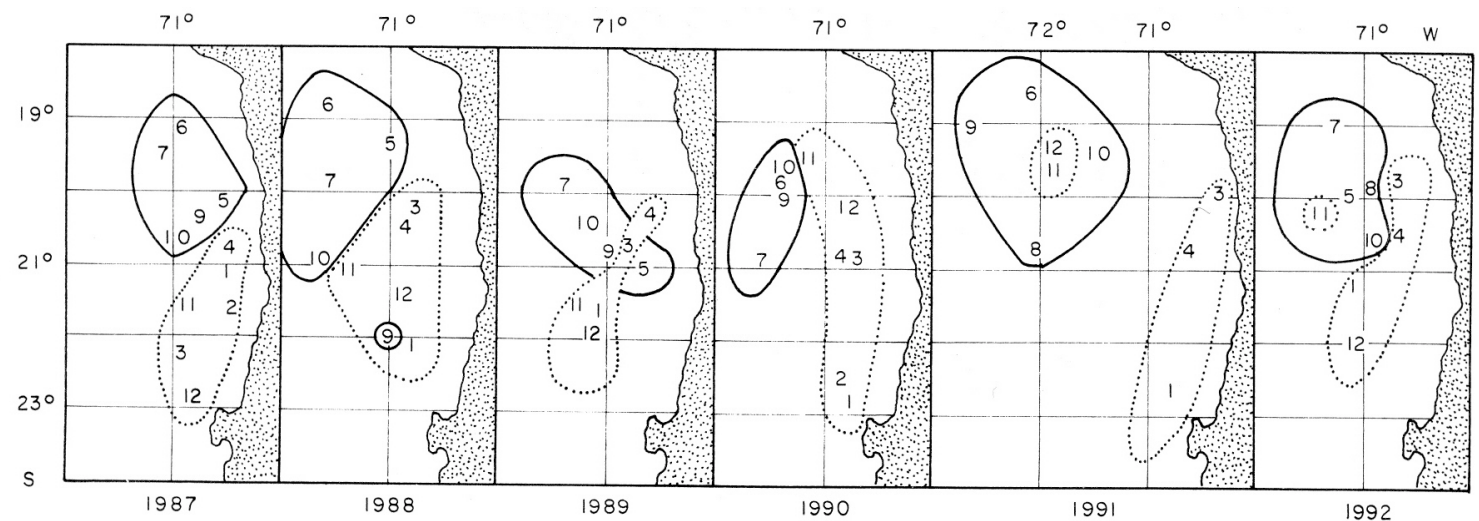

Figura 11. Ubicación de los centros de gravedad de las distribuciones mensuales de CPUE de sardina en la zona norte de Chile (1987-92). 


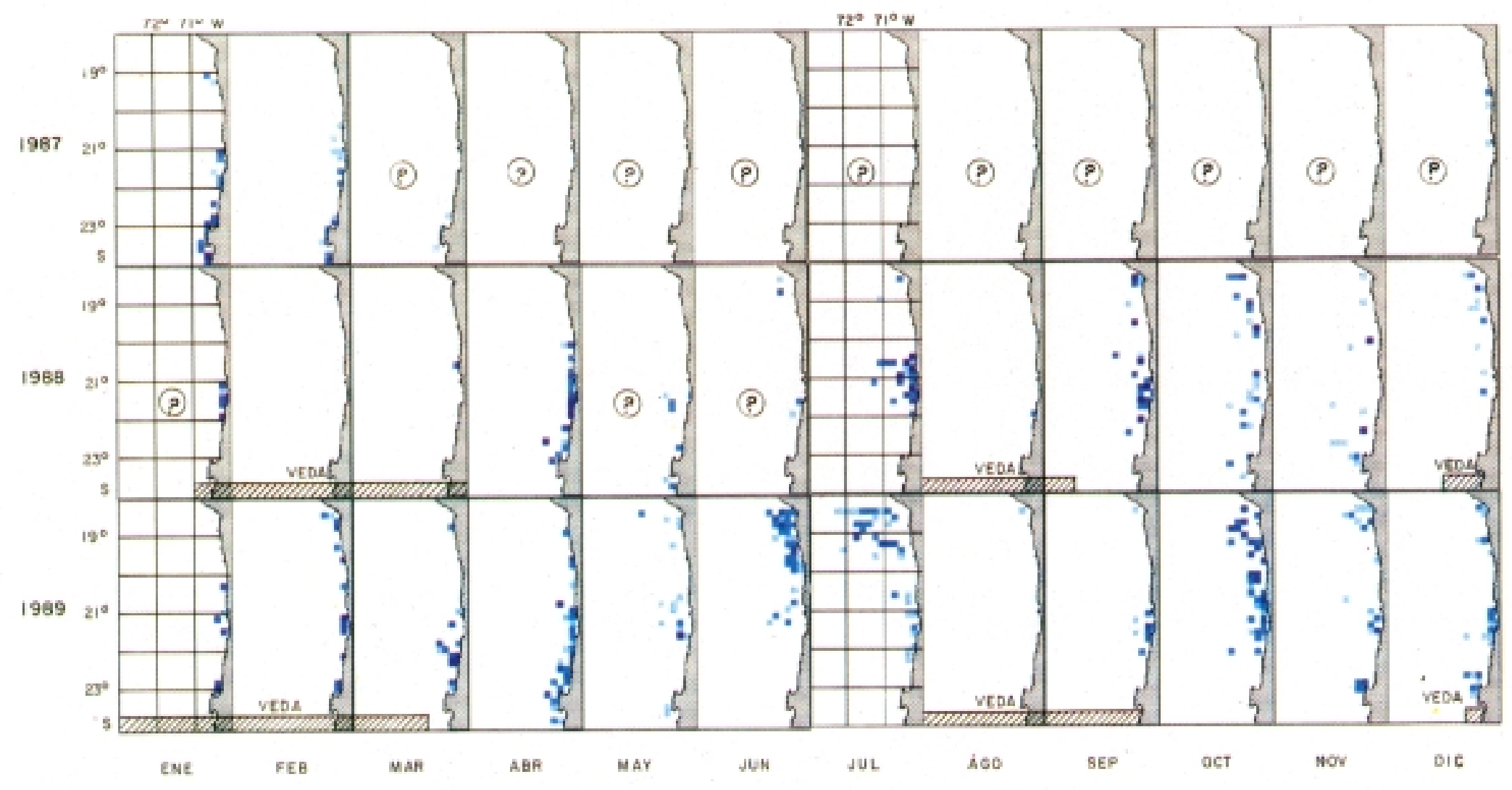

Figura 12a. Distribución espacial y mensual de la CPUE (t/dpe) de anchoveta en la zona norte de Chile: 1987-89. Categorías: a = 0,1-49,9; $b=50-99,9 ; c=100$ 149,9; y d $\geq 150$ (desde celeste claro a azul intenso). Los achurados oblícuos indican períodos de vedas extractivas y el signo? meses con captura total inferior a $35.000 \mathrm{t}$ (salvo enero de 1988 con 127.075 t) (SERNAP, 1987-88). 


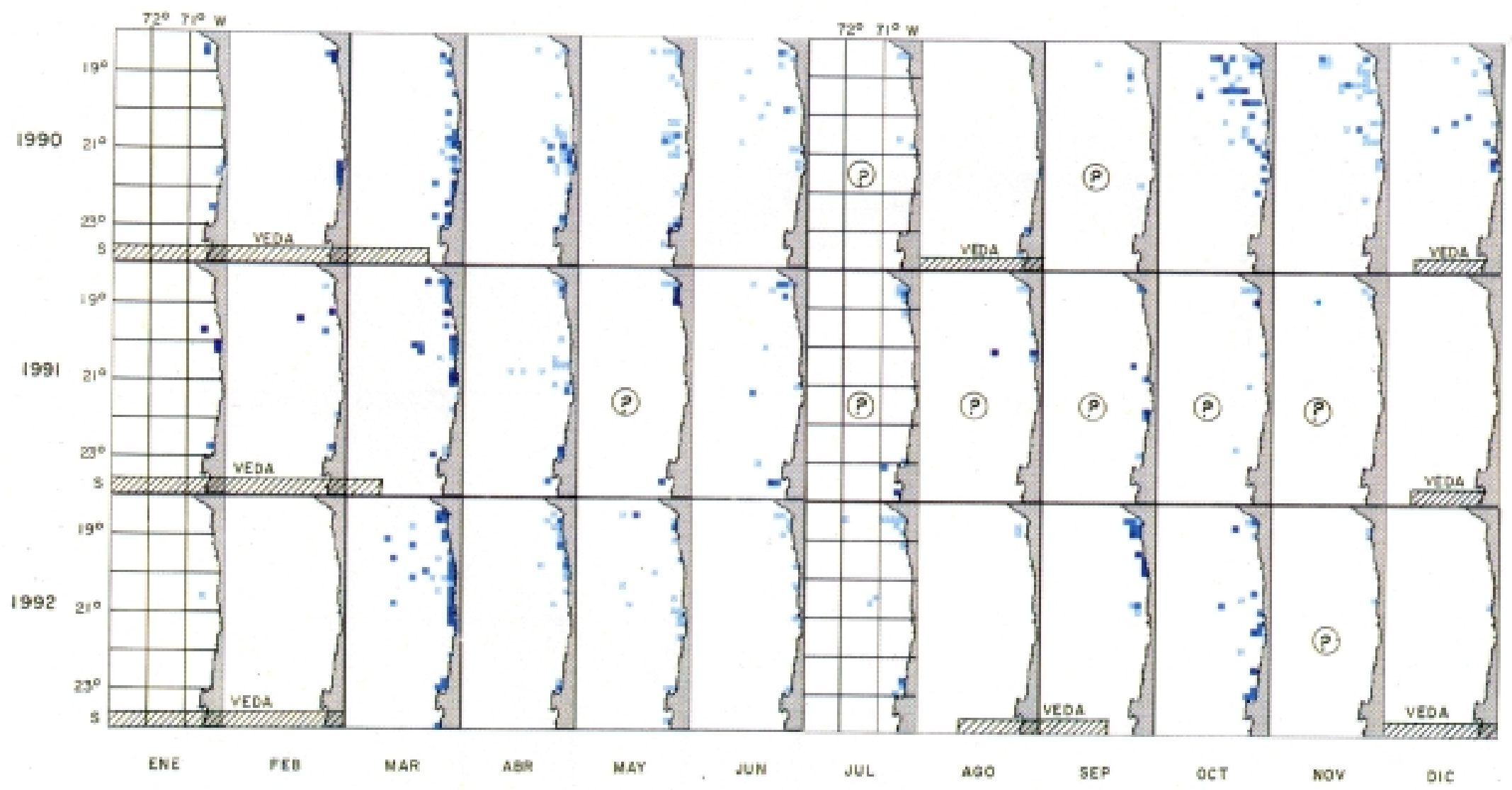

Figura 12b. Distribución espacial y mensual de la CPUE (t/dpe) de anchoveta en la zona norte de Chile: 1990-92. Categorías: a = 0,1-49,9; b = 50-99,9; $c=100-149,9 ;$ y $d \geq 150$ (desde celeste claro a azul intenso). Los achurados oblícuos indican períodos de vedas extractivas y el signo? meses con captura total inferior a 75.000 t (SERNAP, 1990-92). 

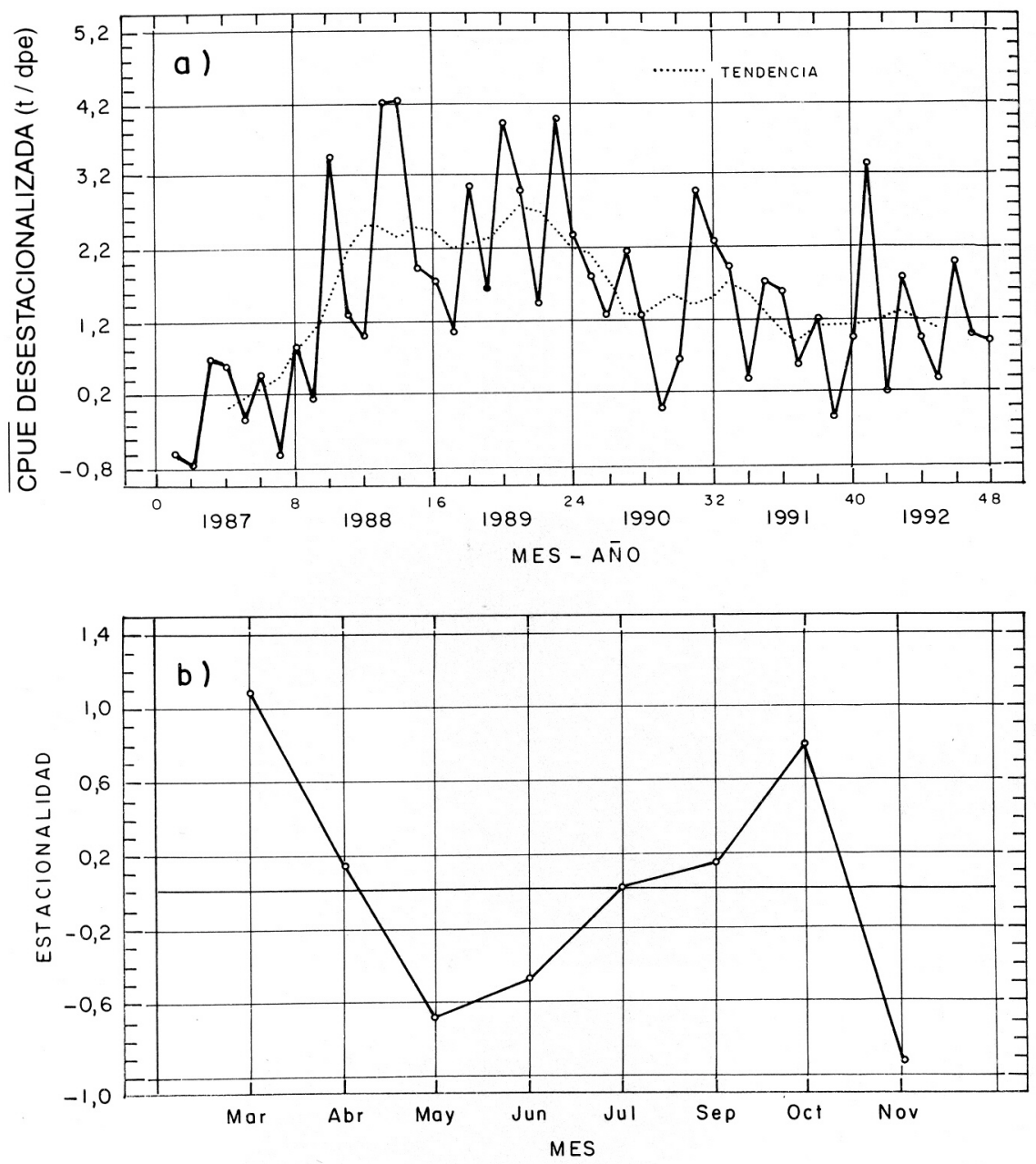

Figura 13. Promedios de las cartografías mensuales de CPUE de anchoveta (1987-92): a) señal desestacionalizada y tendencia, y b) componente estacional (modelo aditivo).

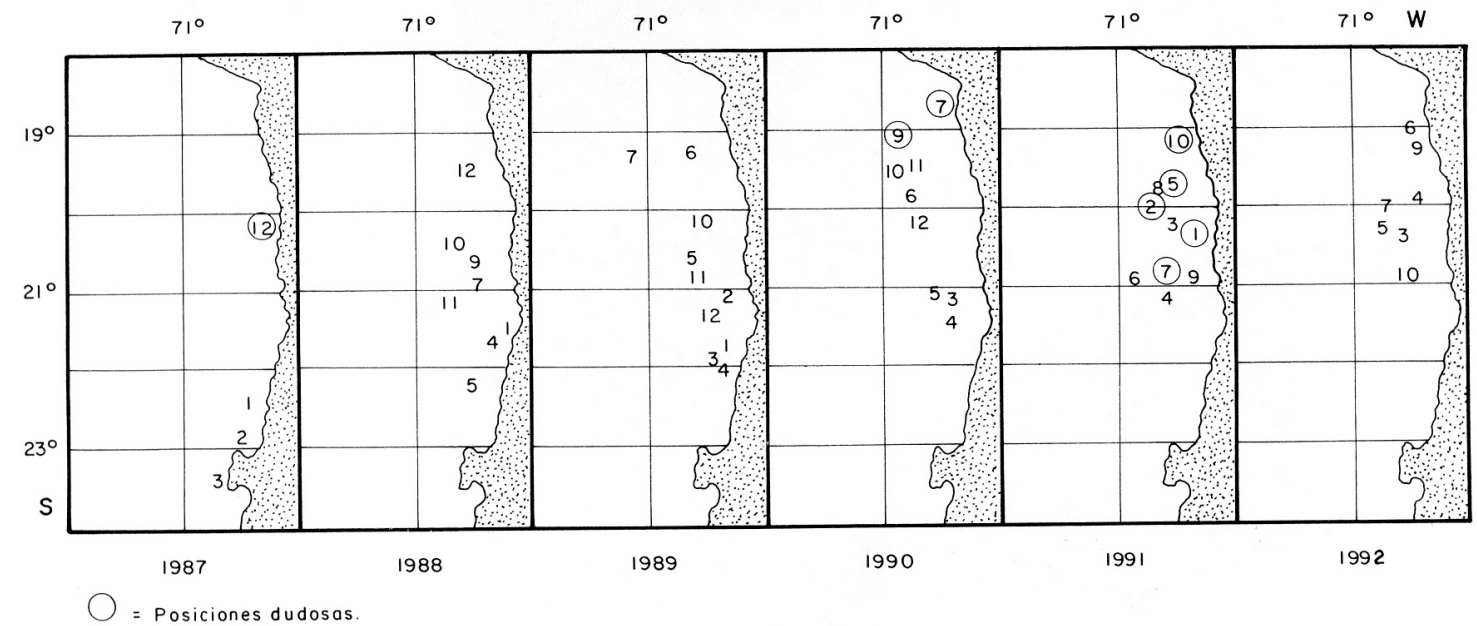

Figura 14. Ubicación de los centros de gravedad de las distribuciones mensuales de CPUE de anchoveta en la zona norte de Chile (1987-92). 

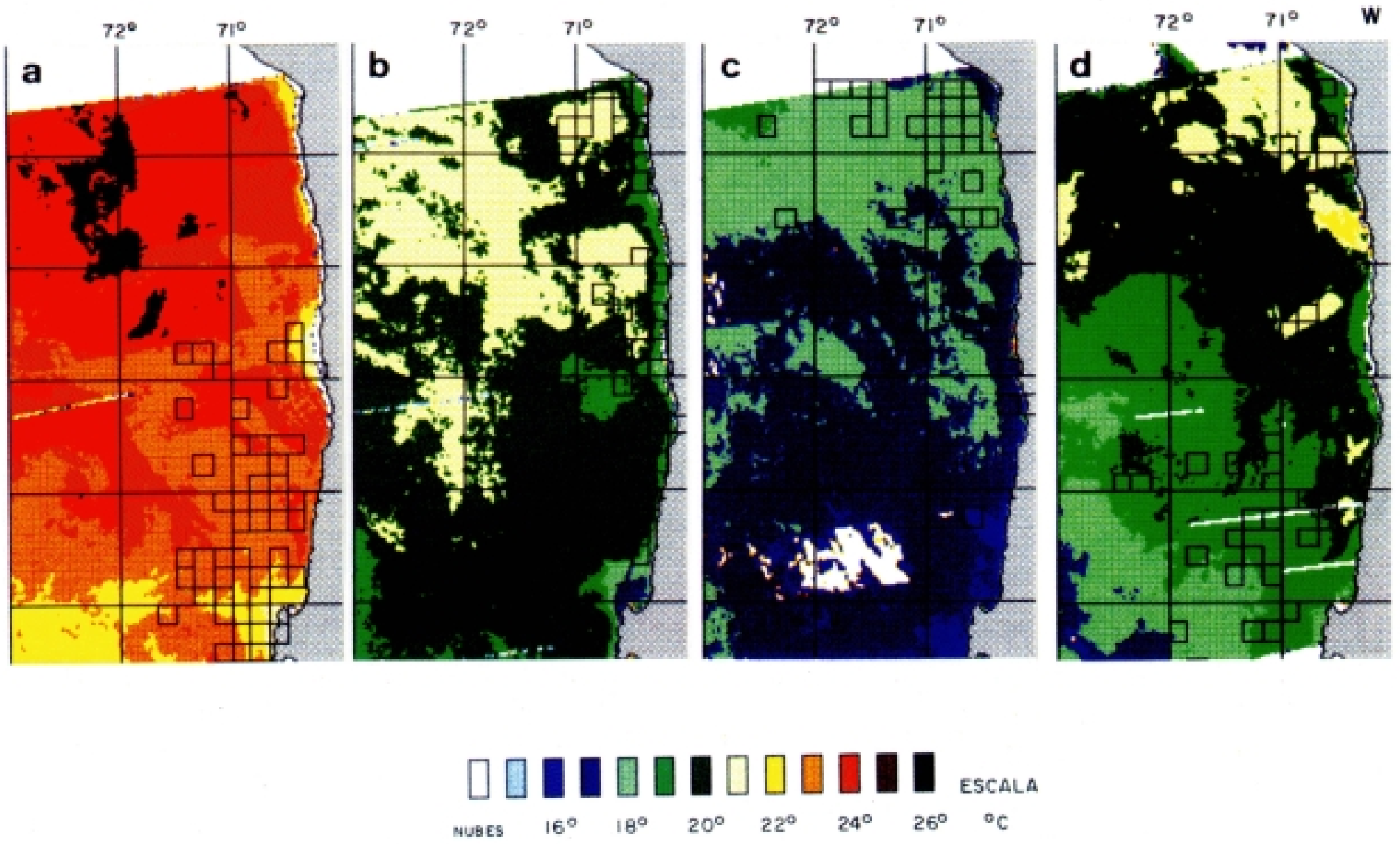

Figura 15. Distribuciones de sardina asociadas a mapas de TSMM en la zona norte de Chile: a) marzo de 1987, b) mayo de 1987, e) junio de 1987, y d) noviembre de 1988 . 

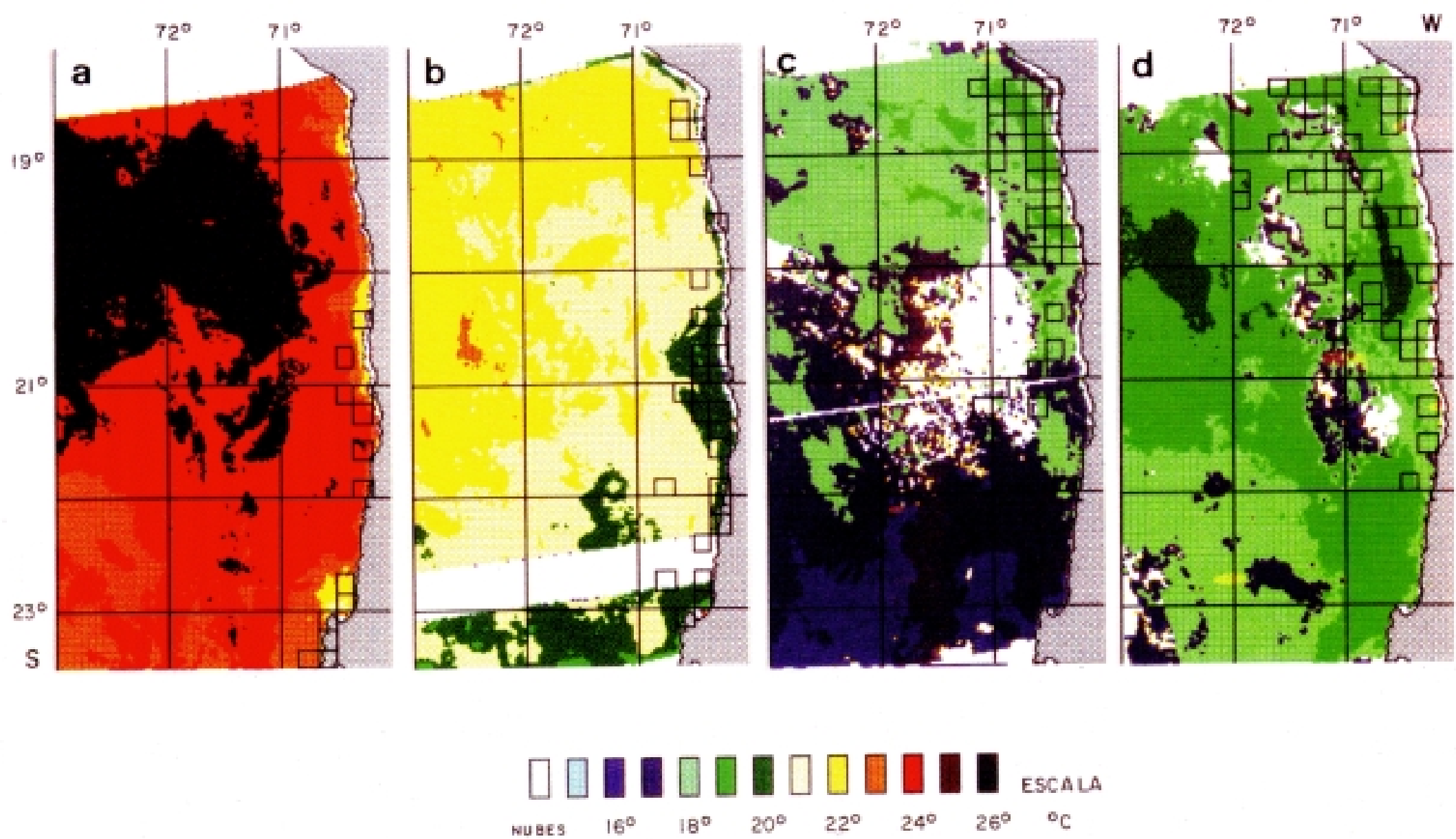

Figura 16. Distribuciones de anchoveta asociadas a mapas de TSMM en la zona norte de Chile: a) febrero de 1987, b) marzo de 1990, e) junio de 1989, y d) noviembre de 1990 . 